\begin{abstract}
THE ROLE OF ATHLETIC IDENTITY AND PASSION IN PREDICTING BURNOUT IN ADOLESCENT FEMALE ATHLETES
\end{abstract}

\author{
by Eric Martin
}

The primary purpose of this study was to determine whether adolescent athletes' levels of sport burnout would be correlated with, or predicted by, their level and type of passion and the degree to which they identify with the athlete role. Measures for burnout, passion and athletic identity were completed by 218 high school female athletes attending summer camps. Two significant canonical functions explained the relationship of the variables. In the first canonical function, high levels of harmonious passion combined with high levels of social identity were predictive of lower levels of burnout on all three dimensions of burnout. In the second canonical function, high scores on obsessive passion combined with high scores on all three subscales of the AIMS were predictive of higher scores on the exhaustion dimension of burnout but lower levels of sport devaluation. Future directions and limitations of the study are also discussed. 


\title{
THE ROLE OF ATHLETIC IDENTITY AND PASSION IN PREDICTING BURNOUT IN ADOLESCENT FEMALE ATHLETES
}

\author{
A Thesis \\ Submitted to the \\ Faculty of Miami University \\ in partial fulfillment of \\ the requirements for the degree of \\ Master of Science \\ Department of Kinesiology and Health \\ by \\ Eric Martin \\ Miami University \\ Oxford, $\mathrm{OH}$ \\ 2011
}

Advisor
Reader
Reader

Dr. Melissa Chase 


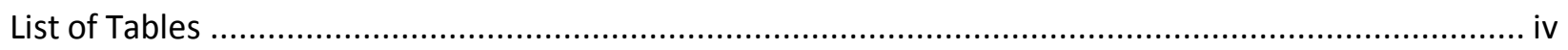

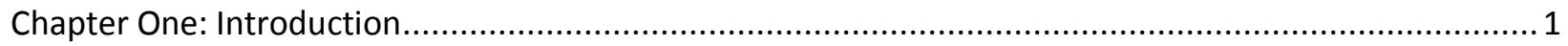

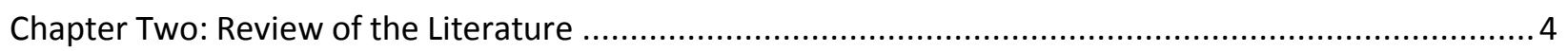

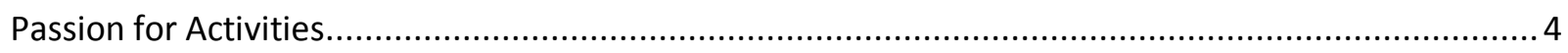

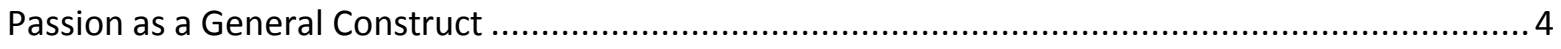

A Dualistic Approach to Passion Towards Activities .................................................................... 5

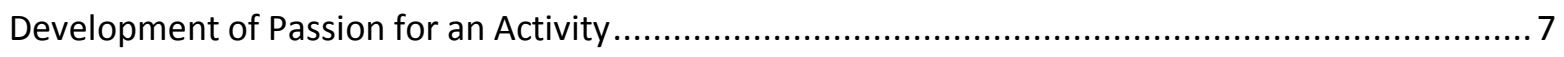

Examination of Correlates of Passion in Specific Activity Contexts........................................... 11

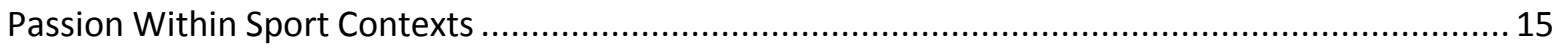

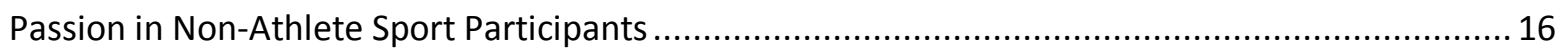

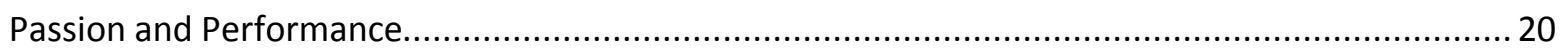

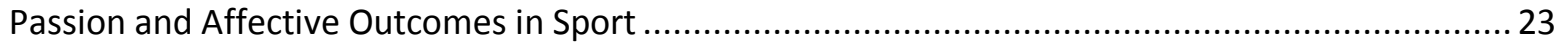

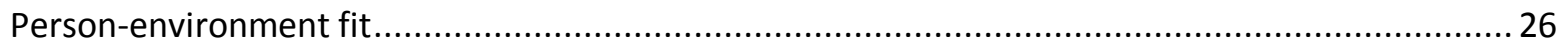

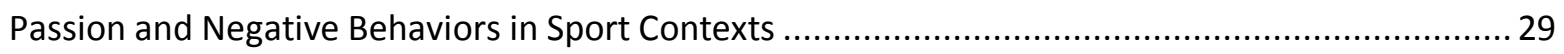

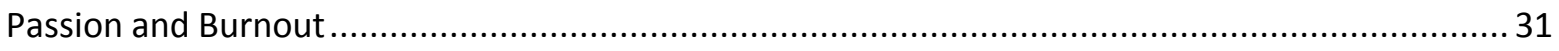

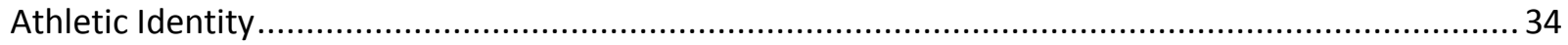

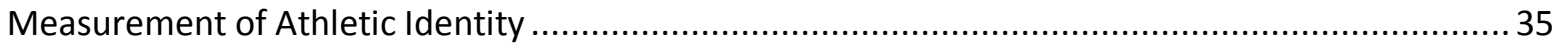

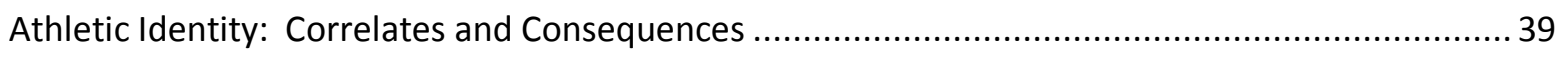

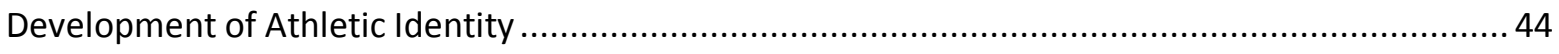

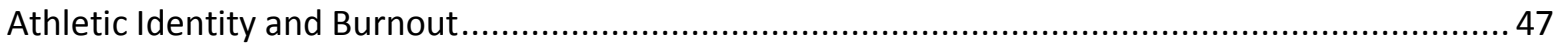

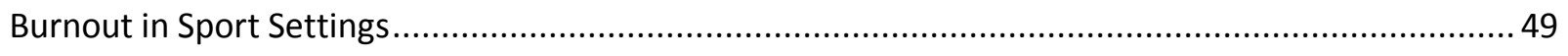

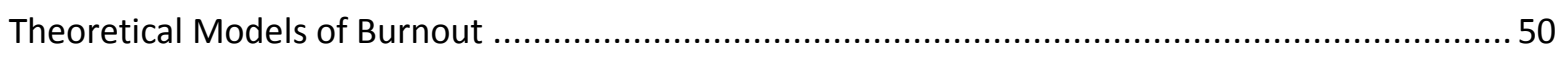

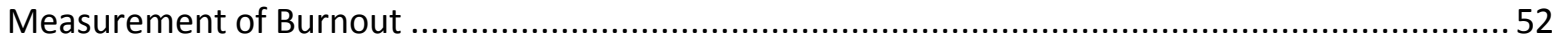

Early Studies on Burnout in Adolescent Athletes ................................................................. 53

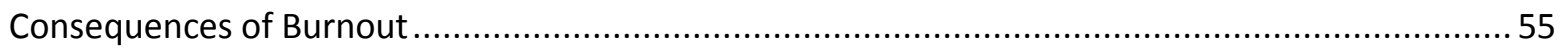

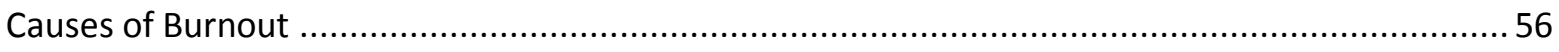

Summary of Literature Review and Overview of Current Proposed Study ...................................5 57

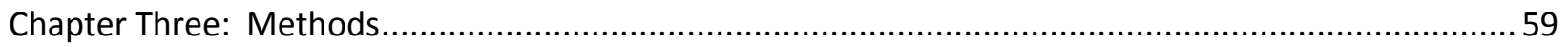

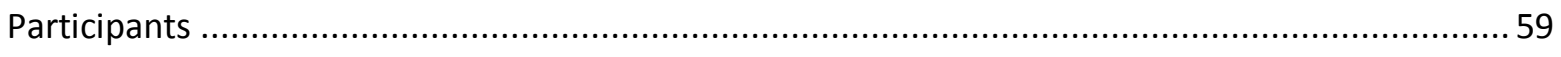


Procedure.

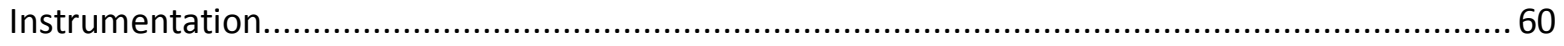

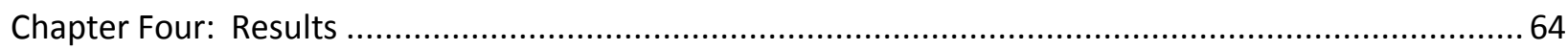

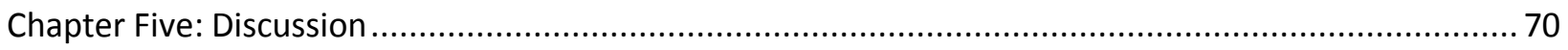

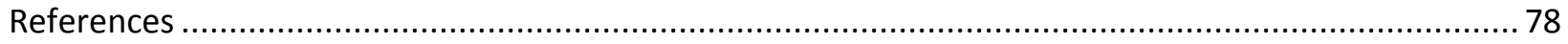




\section{List of Tables}

Page Number

Table 1. Descriptive Data of the ABQ $\quad 87$

Table 2. Descriptive Data of the Passion Scale and AIMS 88

Table 3. Non Significant Academic Level Main Effect 89

Table 4. Correlational analysis for ABQ subscales 90

Table 5. Correlational analysis for Passion Scale subscales 91 and AIMS subscales

Table 6. Follow Up Canonical Correlational Results 92 


\section{Acknowledgments}

To my loving wife for all of her patience and love throughout this process and my mentors and advisors Thelma Horn, Robin Vealey and Melissa Chase for continued guidance and support during my time at Miami University. I could not have asked for more from you as I prepare for the next step of my journey along, what I hope is, a long road in academia. Thank you. 


\title{
Chapter One: Introduction
}

\author{
"Maybe it wasn't talent the Lord gave me, maybe it was the passion" \\ -Wayne Gretzky \\ "I have no special talents. I am only passionately curious."
}

\section{-Albert Einstein}

To reach the pinnacle of a sport an individual must possess at least some natural talent. If an individual is born with below average speed and agility, there is little probability of that person one day suiting up to play for the Los Angeles Lakers or New York Giants.

Correspondingly, however, just because an individual possesses some natural talent does not guarantee him or her success in the sporting realm. Many individuals who had amazing amounts of talent never competed at its highest levels. Often, these athletes do not have the motivation to practice the long hours required for success. Thus, even though talent is an important component of sport success, motivation may serve as an additional requirement for competing at the highest levels in the competitive sport context.

One dimension of athletes' motivation or persistence is their passion. As alluded to in the quotes provided at the beginning of this chapter, both Wayne Gretzky and Albert Einstein, two very successful individuals in very divergent fields, attribute their success more to their passion than to their talents. In particular, they obviously believed that it was the high level of passion that they held for their chosen activity that allowed them to reach the highest pinnacle of success in their chosen field.

Within the research and scholarly literature, passion has been studied primarily from a philosophical perspective (Rony, 1990). In particular, passion has been seen as being either a positive or negative influence on individuals' lives. The first, more negative, perspective is that individuals can be a passive being, or become a "slave", to their passion. The second, more positive, perspective is that passion is a driving motivation that aids individuals in reaching the peak of their abilities. This dual view of passion was not studied in the psychology literature until recently, when Vallerand and colleagues (Vallerand, Mageau, Ratelle, Léonard, Blanchard, Koestner, Gagné, and Marsolais, 2003) conceptualized a dualistic model of passion for an activity. They began by defining passion as "a strong inclination toward an activity that people 
like (or even love), that they find important, and in which they invest time and energy" (Vallerand et al., 2003, p. 757).

In the model proposed by Vallerand and colleagues (2003), passion for an activity can be harmonious or obsessive. Individuals with a harmonious passion feel free to participate in an activity as they choose, and feel no compulsion or coercion to continue in the activity. Individuals with an obsessive passion feel as if their engagement in the activity is out of their control, and the activity eventually takes up a disproportionate amount of their identity. Thus, it ultimately leads to conflict with other activities and roles in their lives. Furthermore, Vallerand et al. contend, that the passion that individuals hold for an activity is dependent on how the activity is internalized into their identity. Harmonious passion results from an autonomous internalization of the activity into the person's identity while obsessive passion results from a controlled internalization of the activity into a person's identity.

Following the introduction of Vallerand et al.'s (2003) passion model, research support has been found for the model in both non-sporting and sporting contexts. In a majority of these studies, harmonious passion has been linked to positive outcomes while obsessive passion has been linked to negative outcomes. In one particular line of research, Vallerand and colleagues (Vallerand, Paquet, Philippe, \& Charest, 2010) found support for a link between passion and burnout in work settings. Specifically, Vallerand et al. found that the type of passion held by workers had a significant impact on their work consequences, with obsessive passion being positively related to burnout while harmonious passion was negatively related to burnout. Furthermore, it appeared that harmonious passion prevented burnout while obsessive passion promoted it. No research has yet been done to examine this relationship between passion and burnout in the sport setting. Thus, a primary aim of the current study was to determine if athletes' level and type of passion would be predictive of their levels of burnout.

A second possible psychological construct that may be related to athletes' burnout levels is their athletic identity. Athletic identity is defined as "the degree to which an individual identifies with the athlete role" (Brewer, Van Raalte \& Linder, 1993, p. 237). Previous research studies have been conducted to examine the link between athletic identity and burnout in adolescent athletes (e.g., Black \& Smith, 2007; Gould, Udry, Tuffey, \& Loehr, 1996; Raedeke, 1997). However, these studies have produced somewhat inconsistent results (i.e., either no link 
or a negative correlation between athletic identity and measures of burnout). Due to these mixed findings, it was deemed important to assess a possible connection in the current study as well.

In summary, then, the overall aim or goal of the current study was to determine whether or not adolescent athletes' level of burnout is correlated with, or predicted by, their level and type of passion and the degree to which they possess an athletic identity. Based on the research and theory to date, it was hypothesized that obsessive passion would be positively related to burnout while harmonious passion would be negatively related to burnout. It was further hypothesized that athletic identity would be negatively related to all three sub-dimensions of burnout.

To test the hypothesized connections, self-report surveys were administered to a sample of high school-aged female athletes. Participants were attendees at summer sport camps and were current participants in a range of sports. All participants, as per IRB approval, were between 16 and 18 years.

To provide a context or background for the current study, the relevant research and theory on the topics are reviewed in the next chapter. This review begins with passion and investigates studies in non-sporting environments as well the sporting context. In the second section, the research and theory on athletic identity are reviewed. In the third section, the topic of burnout, as it occurs in the adolescent sport context, is discussed. 


\section{Chapter Two: Review of the Literature}

Over the past several decades, researchers in the sport psychology literature have examined a number of psychological constructs that may be linked either to the performance of athletes or to their psychosocial well-being. The current proposed study focuses on three of these constructs: passion, athletic identity, and burnout. The review of the relevant research and theory on these phenomena begins with passion.

\section{Passion for Activities}

\section{Passion as a General Construct}

The concept of passion has a long history of study in academia, but primarily in the area of philosophy. In particular, as noted by Rony (1990) in his review of this work, two distinct and opposite perspectives of passion were seen in this literature. The first perspective is more negative in that passion was believed to be a result of a loss of reason and control. This perspective is associated with the notion that people with high levels of passion are seen as "passive" or slaves to their passion. The second perspective was more positive in suggesting that individuals with high passion would be more motivated to reach the highest levels of achievement.

While passion has generated a lot of attention from philosophers (Rony, 1990), it has received little empirical notice in the psychology literature. As Vallerand and his colleagues (Vallerand, Mageau, Ratelle, Léonard, Blanchard, Koestner, Gagné, and Marsolais, 2003; Vallerand \& Miquelon, 2007) noted in recent reviews of this literature, most of the psychologically-based research and theory on passion has focused on its role in the area of romantic relationships (e.g., physical or sexual attraction) or has separated passion into its positive (e.g., motivation) or its negative (e.g., addiction, dependence) effects. Thus, this psychologically-based research perspective has not examined the possibility that passion can be dualistic in nature (i.e., can have both positive and negative effects).

Recently, however, Vallerand and his colleagues (Vallerand, et al., 2003) have proposed a model of passion that does assume a dualistic perspective regarding passion towards activities. Given that competitive sport can be classified as an activity, it appears that this approach may be particularly useful in the sport context. Thus, this dualistic model is described in the following section. 


\section{A Dualistic Approach to Passion Towards Activities}

In proposing their new conceptualization of passion toward activities, Vallerand and associates (Vallerand et al., 2003; Vallerand \& Houlfort, 2003) define the construct as: "a strong inclination toward an activity that people like (or even love), that they find important, and in which they invest time and energy" (Vallerand et al., 2003, p. 757). This definition implies that for an activity to become a passion, it must be significant in individuals' lives, be liked by them, and be something that they engage in frequently. More specifically, the activity that an individual may feel passionate about may not be merely an activity in which she or he participates. Rather, that activity actually becomes a central portion of that person's identity. As Vallerand and his colleagues (2003) note, people who are highly passionate about activities such as football, writing, or teaching, do not merely play football, write or teach. Rather they are, or they have become, football players, writers and teachers.

The dualistic concept of passion (Vallerand et al., 2003; Vallerand \& Houtfort, 2003) posits that two distinct forms of passion exist: harmonious passion and obsessive passion. The type of passion an individual exhibits toward an activity is determined by how the activity is internalized into his or her identity. Harmonious passion results from an autonomous internalization of the activity into the person's identity. This type of internalization has no contingencies associated with the activity, and it is freely accepted by the individual into his or her identity. Autonomous internalization allows the individual to perceive that it is her or his own volition to identify so strongly with that activity, and thus he or she feels no outside pressure to participate. Thus, these individuals feel free to participate in the activity as they choose and feel no compulsion to continue the activity. Furthermore, although the individual realizes that the activity does take a significant portion of her or his time, it still does not overpower other aspects of her or his identity and thus does not cause conflicts with other portions of the individual's life.

Conversely, according to the theory offered by Vallerand and his colleagues (Vallerand et al., 2003; Vallerand \& Houtfort, 2003), obsessive passion results from a controlled internalization of the activity into a person's identity. This type of internalization results from intrapersonal or interpersonal pressures based on contingencies associated with participation of the activity. Intrapersonal pressures may be the thrill received from participation and the uncontrollable urge to participate in the activity. Interpersonal pressure may result from 
increased self-esteem from participation or from feelings of guilt or shame that would come as a result of not participating. The passion construct involves a liking of the activity, and thus individuals who are obsessively passionate do enjoy the activity, but they also feel compelled to participate. Obsessively passionate individuals feel as if their engagement in the activity is, or never was, under their own control, and the activity eventually takes a disproportionate portion of the individuals' identity and leads to conflict with other activities in the person's life.

In order to conduct research studies investigating the construct of passion, Vallerand and his colleagues (Vallerand, Mageau, Ratelle, Leonard, Blanchard, Koestner, Marsolais, 2003) developed a self-report scale they named the Passion Scale. This scale consists of two sevenitem subscales that assess harmonious and obsessive passion. Participant responses are obtained using a Likert-type format. A variety of statistical procedures were used to demonstrate support for the psychometric properties of the scale as it has been used across a variety of settings (see recent review by Vallerand and Miquelon, 2007).

As the definitions of the two types of passion that were described in the previous paragraphs suggest, Vallerand and his associates (Vallerand et al., 2003; Vallerand \& Houlfort, 2003) developed their dualistic approach to passion based largely on Self-Determination Theory (SDT) (Deci \& Ryan, 1985; 2000; Ryan \& Deci, 2000). SDT essentially proposes that individuals' motivational orientation within any particular achievement context (e.g., academics, sports, music) can vary along a continuum that ranges from amotivation (absence of motivation), to external regulation (behavior in achievement context motivated solely by external sources such as punishment, rewards, other people), to internal or intrinsic motivation (behavior in achievement context motivated from an internal source such as wanting to master, learn, acquire). The defining point on the continuum that individuals are at with regard to their motivational orientation for a specific achievement activity relates to the degree to which their orientation is self-determined or non-self-determined. Obviously, at the highest point on the continuum (intrinsic motivational orientation), the individual's behavior is maximally selfdetermined. In contrast, at the lowest points on the continuum (amotivation and external regulation), the individual's behavior is maximally non-self-determined. Furthermore, SDT posits that self-determined forms of motivation are most facilitated in achievement context where individuals perceive competence, autonomy, and relatedness. Vallerand and his colleagues used SDT to develop their dualistic approach to passion and to provide a model specifying the 
development of the two types of passion in individuals engaged in an achievement activity. This developmental perspective is explained in the following section.

\section{Development of Passion for an Activity}

Vallerand and Miquelon (2007) specified a three-step process for the development of passion towards an activity. In the first step, the individual selects (or is recruited/coerced) to participate in an activity. In the second step, the individual develops personal valuation for the activity (i.e., interest/enjoyment). In the third step, the individual internalizes the valued activity by incorporating it into her or his self-identity. But, this internalization can either be of a controlled type (internalizing the activity into one's identity because of perceived external pressure to do so) or of an autonomous type (internalizing the activity into one's identity through personal choice). According to this developmental model, individuals who acquire a controlled internalization subsequently develop obsessive passion while individuals who acquire an autonomous internalization develop a harmonious type of passion.

In accordance with SDT (Deci \& Ryan, 1985; 2000; Ryan \& Deci, 2000), Vallerand and Miquelon (2007) also suggested that the internalization process that occurs at Stage 2 can be affected by the social conditions that are inherent in the activity context. Specifically, individuals who participate in an activity context that promotes their perceptions of competence, autonomy, and relatedness should develop an autonomous internalization and harmonious passion. In contrast, individuals whose participation in the activity occurs within a controlling or coercive context may develop a controlled internalization and an obsessive passion toward that activity.

To assess the links hypothesized in the Vallerand and Miquelon (2007) developmental model, Mageau et al. (Mageau, Vallerand, Charest, Salvy, Lacaille, Bouffard \& Koestner, 2009) conducted a series of studies. The studies investigated the developmental pattern of the two types of passion in individuals who were engaged in a particular achievement activity. This series of studies are summarized in the following paragraphs.

Mageau et al. (Study 1, 2009) explored the relationship between passion and autonomy support and identification in expert-level sport participants and musicians. Based on the Vallerand and Miquelon (2007) developmental model, Mageau and his colleagues hypothesized that individual performers who had reached the expert level would be at risk of defining themselves solely on the basis of the one activity and that they would have developed a more 
obsessive type of passion toward their activity. Study participants included 144 expert level performers (84 musicians, 145 athletes) who had been competing or performing publicly for nearly 10 years and who practiced an average of 21 hours per week. These expert performers completed self-report questionnaires assessing their levels of passion, sense of identity derived from the activity, and perceived autonomy support from social surroundings. Data collection was completed at summer camps or at pre-season training camps. Analyses of the data revealed that all of the participants exhibited high levels of passion for their activity. Mageau et al. suggested that these results may show that passion is an important factor in sustaining efforts to reach an expert level in an achievement activity. Additionally, individuals who exhibited harmonious passion were more likely to report higher levels of autonomy support from their social environment than were those participants who exhibited higher levels of obsessive passion. Furthermore, individuals with obsessive passion appeared to derive a higher sense of identity from the activity than did those with harmonious passion. In general, the results confirmed the researchers' hypothesis in that expert level performers who held a higher identity with regard to their performance activity (music or sports) were more likely to hold an obsessive passion for that activity.

In the second phase of the study, Mageau et al. (Study 2, 2009) again investigated the role of autonomy in the development of passion. Specifically, the researchers had two purposes. The first was to compare the role that autonomy support played in intermediate performers versus elite performers. Second, they wanted to examine the preference of athletes for activity specialization. It was hypothesized that children who had parents who engaged in autonomysupportive behaviors would be more likely to hold a harmonious passion toward their activity and children who desired sport specialization would be more likely to hold an obsessive passion toward the activity. The sample consisted of 163 children and teenagers (mean age $=11$ ) who were registered in a summer camp and who had been involved in an activity for a significant amount of time. Surveys were dispersed to both the children and their parents. The children's survey contained scales to assess their level of passion for their particular activity, degree or level or preference for activity specialization, previous experience with the activity and frequency of activity engagement. The parent survey contained a scale to assess the degree to which they exhibited autonomy supportive parental behaviors and their preference for activity specialization for their children. The researchers found that children in the harmonious passion 
group had parents who were more supportive of their autonomy and valued specialization less than did the parents of those children who scored high on obsessive passion. The investigators used these results to suggest that children who engage in an enjoyable activity under parental autonomy-supportive conditions may be more likely to develop a harmonious passion than will those children who are in a less autonomy supportive environment.

Although the first two studies conducted by Mageau et al. (2009) did provide some information about the developmental processes of passion, these studies were limited in that they were correlational in study design. Unfortunately, correlation, even strong correlation, is not enough to indicate causation. Therefore, in the third study in the Mageau et al. (2009) series, the researchers wanted to follow students from the initial phase of participation in order to identify the conditions that might facilitate the development of passion. The researchers hypothesized that children's identification with the activity, along with preference for specialization as exhibited by both parent and children, and autonomy support from significant adults would be the factors that would prove to be the most conducive to the development of passion in the child. Further, researchers hypothesized that high autonomy support from significant adults would be related to higher levels of harmonious passion while preference for specialization would lead to higher levels of obsessive passion. For this study, Mageau and colleagues followed 196 junior high students enrolled in a music class. These children had no previous background or experience with musical instruments. They were followed for 5 months to determine if passion for the musical activity did develop, and, if so, what factors facilitated the type of passion that developed. Study procedures involved the administration of surveys to the students at three different time points. At the beginning of the semester, the students were given questionnaires that asked about their preference for activity specialization and the sense of identity they derived from the activity. Two months later they were again given questionnaires, but this time the questionnaires assessed the children's perceptions of their parents' preference for activity specialization, the importance they thought their parents had for them playing an instrument, and the level of autonomy support they perceived that they got from their parents. At the end of the semester, children were, again, administered the passion scale to determine if they had developed a passion for the activity. Only $36 \%$ of the students developed either type of passion for playing a musical instrument. Based on these passion results, the sample was divided into three groups: those who were harmoniously passionate, those who were obsessively passionate and those who 
were non-passionate. All three groups' practice times decreased from mid-semester to the end of the semester, but passionate individuals practiced more than non-passionate participants at both mid-semester and end of semester. Individuals who developed passion were also more likely to see the possibility of deriving a sense of identity from the activity, and they valued specialization to a greater extent. They also perceived that their parents valued specialization, and they indicated that they had adults in their lives who were more supportive of their autonomy regarding music and had parents who valued music to a greater extent. In regard to the specific type of passion that was developed, the results of this study showed that children who developed harmonious passion had adults who were more autonomy supportive and valued the activity less. This may suggest that parents who value the activity less put less social pressures on their children to succeed. Furthermore, parents who highly valued the activity and were more controlling were more likely to have children who developed obsessive passion. In addition to the longitudinal results from this study, the researchers also conducted a cross-sectional analysis by comparing the passionate children from study 3 with the expert musicians from study 1 . These results revealed that the expert musicians valued the activity more and reported spending more time with the activity than did the passionate young musicians, but the two groups did not differ in the amount they loved the activity. Expert performers had more harmonious passion than novices. However, the difference in obsessive passion was much more pronounced, with experts having significantly higher levels of obsessive passion as compared to the novices. These finding may indicate that novices need harmonious passion to begin skill building, and once they become experts, it may be more important to have an obsessive passion in order to continue performing.

In summary, then, the studies reviewed in the previous paragraphs do provide at least initial support for the three-stage theory specified by Vallerand and Miquelon (2007) as leading to the development of passion in individuals engaged in an activity. In addition, these study results provide support for the idea that the type of achievement climate (autonomy-supportive or controlling) can affect whether the individual will develop either obsessive or harmonious passion. Other research studies have been conducted to examine the correlates of passion within particular types of activities. These studies are reviewed in the next section. 


\section{Examination of Correlates of Passion in Specific Activity Contexts}

The dualistic model of passion proposed by Vallerand and his associates (Vallerand et al., 2003; Vallerand \& Houlfort, 2003) has been studied in a variety of environments, including gambling, driving, teaching, internet gaming, general internet use and, as discussed later in this chapter, in the sport setting. Researchers chose these contexts because these are all environments where both positive and negative forms of passion and both positive and negative outcomes may be experienced. In particular, the researchers who chose these activity contexts began with the assumption that the type of passion that individuals hold for the activity will determine the type of outcomes they experience. Those individuals with harmonious passion toward the activity will experience more positive outcomes than those who have obsessive passion. Conversely, those individuals that have obsessive passion for the activity will typically experience more negative outcomes than those with harmonious passion.

The dualistic model of passion was first investigated by Rousseau, Vallerand, Ratelle, Mageau, and Provencher (2002) in relation to the activity of gambling and the consequences associated with it. Pathological gamblers have been compared to drug addicts, in that the gambler often loses control over the activity and cannot cease gambling. However, many individuals who do gamble do not show these negative symptoms. To explain this variability, researchers have hypothesized that the differences in the groups are due to the type of passion the individuals held toward gambling. To examine this possibility, Rousseau and his associates developed the Gambling Passion Scale (Rousseau, et al., 2002) that was designed to assess the level and type of passion that individuals had for the activity of gambling. This Gambling Passion Scale, along with measures to assess problematic gambling, were given to 312 adults (mean age $=47.9$ ). The adults were all currently involved in gambling and were recruited at the main entrances of casinos. Results determined that the constructs of obsessive passion and harmonious passion for gambling were independent of each other. Furthermore, Rousseau et al. found that obsessive passion was positively correlated with negative behavioral consequences. In interpreting these results, the researchers suggested that obsessive passion may represent the psychological mechanism for lack of control observed in pathological gambling.

To expand on the previous results, Rattelle, Vallerand, Mageau, Rousseau, \& Provenchar (2004) further investigated the role of passion in gambling. The researchers administered a series of questionnaires that included the Gambling Passion Scale, measures assessing cognitive 
consequences associated with gambling dependence and problem gambling (negative consequences on family life, personal life or work life in adults), and measures of anxiety and guilt to 412 adults (mean age $=47$ ) who were currently involved in gambling activities. The investigators found that obsessive passion for the activity of gambling was positively related with increased ruminations, anxiety, guilt and problem gambling and negatively associated with positive emotions, vitality and concentration. The sample also showed harmonious passion was unrelated to increased ruminations, anxiety, guilt and problem gambling.

In another study investigating gambling behavior, Mageau et al. (Mageau, Geneviève, Vallerand, Rousseau, Ratelle \& Provencher 2005) examined the subjective experiences of gamblers during and after a bout of gambling in relation to the type of passion each individual held for the activity. The researchers predicted that the two types of passion would lead to different cognitive and affective outcomes. A total of 554 adults (mean age $=48$ ) were recruited to fill out the Gambling Passion Scale along with surveys assessing outcomes experienced during engagement and outcomes experienced following engagement in gambling activities. The investigators found that those individuals who held obsessive passion for gambling were more apt to experience negative outcomes during engagement as well as after engagement in gambling. Conversely, individuals who held a harmonious passion towards gambling showed strong positive experiences (e.g., feelings of amusement and fun, perceptions of challenge) during and following engagement in gambling. The investigators also discovered that the more individuals participated in gambling activities, the more inclined they were to report holding some type of passion for the activity. The two passion types mediated the relationship between gambling activity and cognitive affective outcomes with harmonious passion mostly leading to positive outcomes and obsessive passion leading mainly to negative outcomes.

Passion has also been studied in internet gaming. Internet gaming has become increasingly popular especially in the massively multiplayer online (MMO) format, the most popular of this genre being World of Warcraft. In a 2009 research study, Lafreniere et al. (Lafreniere, Vallerand, Donahue \& Lavigne) surveyed 222 players in a MMO environment. These players had participated in this internet gaming activity for, on average, over two years and played an average of 22 hours per week. A call for participants was posted on online forums dedicated to MMO environments. Participants who chose to participate were directed to a website address where they answered surveys about their passion toward gaming, positive and 
negative affect, problematic behaviors, satisfaction with life, self-realization and physical symptoms associated with excessive gaming. Lafreniere et al. found that high levels of obsessive passion toward gaming were related to some positive, but mostly, negative affective experiences while gaming, problematic behavior and negative physical symptoms. In contrast, high harmonious passion was positively related to positive affective experiences, life satisfaction and feelings of self-realization. Again, the researchers speculated that obsessive passion in gaming may represent the psychological mechanism responsible for the lack of control that is often observed in problematic gaming, and obsessive passion may be a precursor to problematic gaming. Even though both harmonious and obsessive passion were significantly related to some positive experiences while gaming, only obsessive passion was shown to correlate with the negative outcomes.

In a related study, Chih-Chien and Yi-Shiu (2007) investigated if passion was related to addiction levels for online gaming. The researchers hypothesized that obsessive passion would be related to levels of addiction while harmonious passion would be unrelated. A call for participants was posted online on a well-known online game virtual community in Taiwan. Participants were directed to a survey that measured passion levels as well as internet gaming addiction levels. A total of 404 participants completed the survey with the average age of participants being 18.23 years. Analyses of results revealed that obsessive passion is associated with negative outcomes for gamers, with obsessive passion highly correlating to online game usage and online addiction. Harmonious passion showed no significant relationships to either game usage or online players' addiction.

The relationship between driving and passion has been recently studied as well. Philippe et al. (Philippe, Vallerand, Richer, Vallières, \& Bergeron, 2009) conducted a series of studies that investigated the relationship of passion and driving, specifically aggressive driving. In the first study, the researchers hypothesized that those individuals who held an obsessive passion toward driving would engage in maladaptive driving behaviors more frequently than would individuals who had a harmonious passion toward driving. The sample consisted of 133 undergraduate students and each completed surveys that assessed their passion for driving, and their aggressive driving behavior. As predicted, obsessive passion was associated with all types of aggression while harmonious passion was unrelated to these same variables. 
In the second study, Philippe and colleagues (2009) conducted a similar project with a more ecologically valid sample. Specifically, a random sample of 458 adults from a metropolitan area were given surveys that assessed their passion for driving, aggressive driving behavior and aggressive reactions to a recent frustrating driving situation. Again, as predicted, the data showed that obsessive passion was positively related to all three types of aggression while harmonious passion was unrelated.

The third and final study conducted by Philippe et al. (2009) tested the relationship between passion and aggressive driving within a laboratory context. Researchers predicted that those individuals with obsessive passion would have higher self-reported aggressive driving behavior. In addition the researchers believed that individuals with obsessive passion would display higher aggressive driving tendencies in the lab setting. Participants were recruited through advertisements in driving magazines and on auto related internet sites. The sample consisted of 44 young men. Prior to the experiment each participant filled out surveys assessing their passion for driving, anger in driving and self-reported aggressive driving behaviors. The researchers then set up a driving experiment with two sections. In both sections of the study the participants were told they were driving to an appointment and should, if possible, arrive on time. The first section of the study had each participant try to pass a car in front of them. However, the car was programmed to not allow the participant to pass them and would either speed up if the participant switched lanes to pass them or slow down if the participant was behind them. In the second portion of the experiment the participant was stuck behind a nonmoving truck in the right lane of a two-lane highway with cars passing in the left lane and the participant was unable to get around the non-moving vehicle. The researchers found that obsessive passion was significantly and positively associated with both the self-report and observed measures of aggressive driving behavior while, again, harmonious passion was unrelated. Obsessive passion positively predicted aggressive driving behavior during the first part of the laboratory task (inability to pass car) while the only significant predictor of aggressive driving behavior in the second lab task was anger. However, obsessive passion for driving fully mediated this relationship.

The studies described in the previous paragraphs examined the link between passion and mostly negative behaviors (e.g., gambling, aggressive driving). From a more positive perspective, Rousseau and Vallerand (2008) wanted to study the relationship between passion 
and subjective well-being in older adults. They recruited volunteers from a club for active older adults, and each participant was asked to fill out surveys at three different time points (T1, T2five weeks later and T3-eight weeks following initial survey). Only individuals who completed all three time points were included in the analyses. Thus, the final study sample consisted of 119 participants. In the first questionnaire the participants were asked to answer questionnaires concerning their passion levels about a given activity, their subjective well being, and global life satisfaction. The second questionnaire assessed positive and negative affect and the third set of questionnaires again assessed their global life satisfaction. After controlling for harmonious passion, it was found that obsessive passion was negatively correlated to subjective well-being at time 3. Similarly, after controlling for obsessive passion, harmonious passion was positively correlated to subjective well-being at time 3 . Harmonious passion was also positively correlated with positive affect at time 2 , which in turn was positively associated with subjective well-being at time 3. Obsessive passion was positively associated to negative affect at time 2 and in turn negatively associated with subjective well-being at time 3 . These results, then, support the idea that older adults who participate in an activity for which they hold harmonious passion have higher levels of subjective well-being. In contrast, older adults whose passion toward a particular activity is of an obsessive type tend to experience decreases in subjective well-being.

In general, then, the studies reviewed in the previous paragraphs provide support for the dualistic approach to passion that was proposed by Vallerand et al. (2003) and Vallerand and Houlfort (2003). In particular, the results of these studies do suggest that there are two types of passion and that the two types are differentially related to individuals' behavior and psychosocial well-being in a variety of activity settings. As noted previously, some research studies have also been conducted to examine passion in the sport context. These studies are reviewed in the following sections of this chapter.

\section{Passion Within Sport Contexts}

In the years since the publication of Vallerand and colleagues' (Vallerand et al., 2003; Vallerand \& Houlfort, 2003) dualistic approach to passion, a number of studies have been conducted to examine components of passion within the general sport and physical activity context. These studies have been conducted across a range of sports, age and competitive levels, and have focused on different implications drawn from the dualistic model. For purposes of this

project, these studies have been grouped in to sub-categories and are discussed in the following 
sub-sections. It should also be noted that most of the studies included in the following subsections were conducted with athletes however, a few included individuals from other achievement (but still performance-related) settings.

\section{Passion in Non-Athlete Sport Participants}

Usually when sports are investigated in the literature, players or coaches are the principle participants. However, for many individuals, sports play an important role from a spectator perspective. In particular, committed or passionate fans may experience a variety of emotions (both positive and negative) in relation to how "their" team performs. In recent years, Vallerand and colleagues (Vallerand, Ntoumanis, Philippe, Lavigne, Carbonneau, Bonneville, LagaceLabonte \& Maliha, 2008) conducted a series of studies that investigated the role passion plays in the lives of sports fans.

Vallerand et al. (Study 1, 2008) tested the dualistic passion model with football fans from the United Kingdom. For this study, the researchers hypothesized that both harmonious and obsessive passion would be related to celebration of victories by the team. However, they further hypothesized that only harmonious passion would be associated with life satisfaction while obsessive passion would be related to maladaptive behaviors. A sample of 165 fans (1875 years, mean $=30.8$ ) recruited from outside football stadiums, or in other public places where sports fans gathered, completed questionnaires that assessed the passion they felt for their team, their identity as a sports fan, the type of celebration behaviors in which they engaged, maladaptive behaviors, and life satisfaction. The analyses of the results indicated that individuals' level of both harmonious and obsessive passion for their team was positively correlated to fan identity and to fans' willingness to celebrate their team's victories. However, only harmonious passion was positively correlated to life satisfaction, while only obsessive passion was positively related to maladaptive behaviors. Obsessive passion was also significantly correlated to negative cognition and behavior, difficulty recovering after a loss and the inability to concentrate on game day.

Vallerand et al. (Study 2, 2008) investigated the role passion played on individuals' positive and negative emotions during a single, very significant event, namely the 2006 World Cup. The study had multiple purposes: (a) expansion of the original findings from the English only sample used in Study 1 to a North American sample; (b) study of the role passion plays in positive and negative emotions during a specific event; (c) study of the relationship between 
passion and subjective well-being in fans; and, (d) to better understand the differences in how fans celebrate victory. For their study, the researchers recruited 242 football fans, who were supporters of Italy and France, the two teams that were participating in the 2006 World Cup. These fans were asked to complete a questionnaire that assessed their level of passion for their team, the identity they felt with their team, positive and negative emotions, fan behaviors, satisfaction with life, and self-esteem. Study results revealed that both types of passion predicted the emotion of pride in the World Cup fans, but only obsessive passion predicted the emotion of hate toward the opponents, along with other negative emotions following the game. Only harmonious passion was related to fans' perceptions of their own well-being and overall selfesteem.

In the third study in the series (Vallerand et al., 2008), the researchers investigated the role that passion for one's football team plays with an interpersonal outcome outside of football, specifically the satisfaction of one's partner relationship. It was hypothesized that individuals with obsessive passion would experience more conflict with their significant other and have lower perceived quality of partner relationships due to the additional life conflict that can occur when an individual has obsessive passion toward an activity. Spectators from a football stadium were recruited for the study. In total 144 spectators completed a questionnaire that assessed their passion for their team, the degree of conflict with their significant other, satisfaction with their partner relationship, and perceived problems with finding a partner due to football. The researchers found that obsessive passion was positively correlated to conflict in a romantic relationship. Furthermore, for single individuals, the study results suggested that obsessive passion may make it difficult to find and remain in a romantic relationship.

As demonstrated in the previous paragraphs, the studies by Vallerand et al. (2008) show initial support for the dualistic model of passion for sports fans. The research for passion on non-athletes also has been extended to another group commonly ignored outside of the typical coaches and participants; referees. The following paragraph will review two studies conducted by Philippe et al. (Philippe, Vallerand, Andrianarisoa \& Brunel, 2009) that investigated the relationship that passion for refereeing plays in an individuals' life.

Philippe et al. (Study 1, 2009) wanted to investigate the consequences of passion on referees' affective and cognitive functioning during game scenarios. It was hypothesized that individuals with harmonious passion would be more likely to have positive emotional 
experiences during a game while those with obsessive passion would experience more negative emotions. The sample consisted of 238 referees in France from either an elite group (national and international officials) or a non-elite group (regional and local officials). Both groups were given The Passion Scale, along with measures for flow and positive and negative emotions. Both of the groups scored moderate to high on passion for refereeing, with $95 \%$ indicating at least moderate levels. In regard to type of passion, elite referees were found to score higher on harmonious passion than the non-elite officials, but no differences between the elite and non-elite were found for levels of obsessive passion. Officials with harmonious passion were more likely to experience flow, as well as positive emotions, during contests than were those who exhibited obsessive passion.

In the second study (Philippe et al., 2009), the researchers wanted to expand the previous study by examining the affective functioning of officials in distressing situations, specifically after an obvious error. It was hypothesized that harmonious passion would be unrelated to negative emotions, and stress while obsessive passion would be positively related to negative consequences. A sample of 227 football officials from France participated in the study. Officials were working in the low to moderate level football leagues in France. Participants were asked to complete The Passion Scale, and a questionnaire assessing their cognitive and affective responses following an error. Officials with harmonious passion made a neutral decision following an error while those that had obsessive passion were more likely to make imbalanced decisions and experience negative emotions. Philippe et al. discussed these results by suggesting that harmonious passion may protect officials from negative cognitive emotions associated with making an error.

As demonstrated by the previous studies there is preliminary evidence to support the fact that the type of passion referees holds towards refereeing can impact how they experience their work as well as how they react to an error. There have been two studies that have investigated the role passion plays for coaches (Lafrenière, Jowett, Vallerand, Donahue \& Lorimer, 2008). One of these studies investigated coaches' passion from the athlete perspective and the other from the coach's perspective. These studies are summarized in the next paragraphs.

Lafreniere et al. (Study 1, 2008) focused on the role of passion in the coach-athlete relationship from the athletes' perspective. The researchers hypothesized that harmonious passion would predict a high-quality relationship with the coaches while obsessive passion 
would be less predictive of the relationship quality. Participants were 157 British college athletes. Each participant completed measures for passion as well as the Coach-Athlete Relationship Questionnaire (CART-Q) which contains three subscales: commitment (measures the athlete's intention to maintain the athletic partnership over time); closeness (assesses the affective tone of the relationship); and complementary (assesses cooperative actions of the relationship). The study results revealed that athletes' levels of harmonious passion were significantly and positively related to all subscales of the CART-Q, indicating higher quality coach-athlete relationships. In contrast, athletes' scores on obsessive passion were significantly and positively correlated to the commitment subscale but negatively related to the closeness and complementary subscales. These results provided general support for the study hypotheses regarding the positive effects of harmonious passion, and the corresponding negative effects of obsessive passion, on the coach-athlete relationship.

While the first study conducted by Lafreniere et al (2008) looked at the passion levels of coaches from the athletes' perspective, the follow-up study (Study 2) focused on the coaches' perspectives. It was hypothesized, again, that harmonious passion on the part of coaches would be positively correlated with high-quality coach-athlete relationships while obsessive passion would be unrelated to it. The sample consisted of 106 French-Canadian coaches and each were given a questionnaires pertaining to their level and type of passion, situational positive emotions, coach-athlete relationship, satisfaction with life and general positive and negative affect. The researchers found that coaches' levels of harmonious passion were positively related to situational positive emotions, which were positively related to interpersonal relationship quality that, in turn, was positively related to subjective well-being. Obsessive passion was unrelated to situational positive emotions.

Both of the studies conducted to examine the link between passion and the coach-athlete relationship show that harmonious passion was predictive of high-quality coach-athlete relationships while obsessive passion was predictive of less-than optimal coach-athlete relationships. Possible reasons for this relationship may be that individuals who have harmonious passion would be more likely to be open to their environment, and this openness might facilitate the experiences of positive emotions during engagement. These positive emotions then lead to positive interpersonal behaviors such as smiling, positive sharing of the 
activity, connection and openness. These conditions, created by those with harmonious passion, would, then, be more conducive to a more positive interpersonal relationship.

The correlates and consequences of passion in the sporting environment have been studied from the perspectives of many individuals besides athletes. This includes fans, referees and coaches. Of primary interest to the current proposed study is the effect of passion in athletes. In the next section, the research on the dualistic model of passion in regard to athletes themselves is reviewed.

\section{Passion and Performance}

In the competitive sport setting, performance is obviously a primary outcome variable. Thus, at some point, all (or certainly most) psychosocial variables that are studied by sport psychology researchers are ultimately tested for their impact on athletes' actual performance. Vallerand and his colleagues (Vallerand, Salvy, Mageau, Elliot, Denis, \& Grouzet, 2007) conducted a series of studies to examine the link between passion and performance. Although some of these studies focused on performance in sport contexts, others examined performance in non-sport activity areas.

Vallerand et al. (Study 1, 2007) wanted to test the relationship that passion had with both subjective well being and measures of deliberate practice (demanding, repetitive and not always enjoyable activities where external or monetary rewards are rarely present) and performance. The researchers hypothesized that both types of passion would be related to deliberate practice and performance, but only harmonious passion would be related to subjective well-being. A sample of 143 students attending a prestigious and selective dramatic arts school were asked to fill out measures of passion, subjective well-being, and the amount of deliberate practice in which the students engaged. One month later the school instructors were asked to provide a rating of for each students based on their dramatic arts performance. The results were consistent with the hypothesized model. Both types of passion predicted amount of deliberate practice which, in turn, was found to predict performance. However, only harmonious passion was associated with an increase in subjective well-being in the theater students.

In the second study, Vallerand and colleagues (2007) wanted to further investigate the role that passion plays in regard to amount of deliberate practice and subjective well-being, but they also added measures of goal orientations in individuals. The researchers hypothesized that passion would lead to higher amounts of deliberate practice which would lead to higher 
performance. Furthermore, consistent with the results of the previous study, they again hypothesized that only harmonious passion would be positively associated with subjective wellbeing. Lastly they proposed that a task orientation would be associated with harmonious passion, and an ego orientation would be associated with obsessive passion. A sample of 130 undergraduate students enrolled in a specialized psychology program was asked to complete a questionnaire that assessed passion, achievement goals, deliberate practice and subjective wellbeing. A performance measure was attained by summing the students' scores on their mid-term and final exams in their psychology class. The results of this study showed that harmonious passion positively predicted the use of mastery goals while obsessive passion was shown to predict not only mastery goals but also performance goals. Mastery goals predicted both short term and long-term deliberate practice, that were, in turn, direct positive predictors of performance. Harmonious passion was positively related to subjective well-being while obsessive passion was negatively related to it. Even though both harmonious and obsessive passion indirectly facilitated performance attainment through deliberate practice, only harmonious passion was shown to be positively related to well-being in the participants.

Vallerand et al. (Vallerand, Mageau, Elliot, Dumais, Demers, Rousseau, 2008) extended the research on passion and performance attainment by conducting two studies in the sporting context. Their earlier studies (Vallerand et al., 2007) described in the previous paragraphs showed that passion represents a major motivational force that leads one to engage in deliberate practice, and deliberate practice has been shown to be a key component in mastering an activity. Thus, Vallerand et al. (2008) hypothesized that the role of passion could also play a large role in the development of sport skills. These studies are reviewed in the next paragraphs.

Vallerand and colleagues (Study 1,2008) wanted to test a model that would investigate the effect that passion might have on deliberate practice as well as the relationship between deliberate practice and performance. The researchers hypothesized a model that proposed that both harmonious and obsessive passion would lead to deliberate practice and that deliberate practice would be related to performance. The hypothesized model made the assumption that passion provided the spark for individuals to engage in deliberate practice, and deliberate practice had direct influence on performance attainment. The study sample consisted of 184 high school basketball players who completed questionnaires containing measures for passion and deliberate practice prior to the first game of a regional tournament. Following the first game 
of the tournament, coaches rated their players on their performance. Results were consistent with the hypothesized relationships. Both types of passion predicted deliberate practice, which in turn, predicted performance.

In a subsequent study, Vallerand et al (Study 2, 2008) again investigated the role that passion plays in predicting deliberate practice but also examined the effects of achievement goals, particularly as those goals might serve as mediators of the passion-deliberate practice relationship. The researchers hypothesized a model where harmonious passion would be associated with only mastery goals while obsessive passion would be related to mastery goals, performance-approach goals and performance goals. Further, they hypothesized that only mastery goals would lead to deliberate practice, and the researchers believed that only harmonious passion would be related to subjective well-being. The sample consisted of 67 competitive water polo and synchronized swimming athletes. Each participant was asked to fill out a questionnaire assessing passion, subjective well-being, achievement goals, and deliberate practice. For the performance related measure, coaches were asked to assess the athletes on their performance. The results supported the hypothesized model. Harmonious passion only correlated with mastery goals while obsessive passion was correlated with mastery goals, performance-approach goals and performance goals. Only mastery goals were positively correlated with deliberate practice. Performance-approach goals were unrelated to deliberate practice and performance goals negatively correlated with deliberate practice. Only harmonious passion was associated with increased levels of subjective well-being. Both harmonious passion and obsessive passion were associated with mastery goals that led to positive outcomes in the form of deliberate practice, but only obsessive passion was related to self-defeating goal setting strategies. Also, only harmonious passion was positively associated with subjective well-being. The type of passion that athletes hold does seem to be important in predicting the types of goals they hold for their activity as well as the positive benefits they gain from activity engagement.

In general, the initial studies conducted by the researchers cited in the previous paragraphs indicate that the type of passion an individual holds for an activity may dictate the amount of deliberate practice they are involved in as well as the consequences that are associated with participation. Even though both harmonious and obsessive passion were related to deliberate practice, the type of passion the individual held for that activity was related to related other consequences. Harmonious passion was solely related to positive outcomes while 
obsessive passion was related to negative outcomes. Another way to examine the importance of passion in the sport setting is to examine the relationship between the passion construct and athletes' affective states. These studies are described in the next section.

\section{Passion and Affective Outcomes in Sport}

As noted earlier in this chapter, Vallerand and his colleagues (Vallerand, Mageau, Ratelle, Léonard, Blanchard, Koestner, Gagne, \& Marsolais, 2003) developed and tested the Passion Scale that could be used to assess individuals' passion for an activity. As part of this psychometric work, these researchers also examined the links between individuals' levels of passion and their affective outcomes. These studies, as well as others that were conducted specifically to examine whether or not the two types of passion are linked to different affective outcomes are described in the following paragraphs.

Vallerand et al. (Study 1, 2003) conducted their first study to establish initial validity for their general passion scale and to investigate constructs that might be related to each type of passion and/or might be differentially affected by the two types of passion. In particular, the researchers hypothesized that harmonious passion would be related to positive outcomes and obsessive passion would be related to negative consequences. A sample of 539 college students were given the passion scale and asked to answer the scale in relation to an activity that they held important and that took up a significant portion of their time. In addition to The Passion Scale the students were asked to answer questionnaires that assessed activity valuation, and outcomes of participation. These potential outcomes included feelings of flow (Czikszentmihalayi, Rathunde, \& Whalen, 1993), positive and negative emotions and feelings following participation. The results of the study showed that harmonious passion was positively related to the feeling of flow, positive emotions, and task focus. Conversely, obsessive passion was associated with conflict in other aspects of one's life and negative emotions. Furthermore, when individuals were prevented from engaging in the activity about which they were passionate, negative affect (e.g., guilt, anxiety and negative cognitions such as ruminating about the activity) was associated with obsessive passion, but these negative affective feelings were unrelated to harmonious passion.

Vallerand et al. (Study 2, 2003) expanded their research on passion and affective outcomes by examining the role of passion in predicting changes in general positive and negative affect over the course of an entire football season. The researchers hypothesized that 
harmonious passion would, throughout the course of a season, be associated with increased positive affect and intentions to continue in the activity. Vallerand et al. also hypothesized that obsessive passion would be unrelated to general positive affect but would be associated with negative affect and intention to discontinue sport participation. The study sample consisted of 205 male football players in an intercollegiate football league and each filled out measures for passion, intrinsic and extrinsic motivation, positive and negative affect and intentions for participation next season. The results of this study provided partial support for the hypotheses. Specifically, harmonious passion was associated with increases in positive affect over the course of the season, and obsessive passion was associated with increases in negative affect during the same time period. Higher obsessive passion predicted a decreased intention to continue participation in football, while harmonious passion was unrelated to intention to continue.

A few years later, Vallerand et al. (Vallerand, Rousseau, Grouzet, Dumais, Grenier, \& Blanchard, 2006) continued their work on the determinants of passion in a sporting environment. In particular, they used self-determination framework, (Deci \& Ryan, 1985; 2000) to investigate the role that passion might play in satisfying humans' basic psychological needs of autonomy, competence and relatedness. These studies are reviewed in the following section.

In the first study, Vallerand et al. (Study 1, 2006) hypothesized that individuals exhibiting a controlled personality orientation combined with high sport valuation would score high on obsessive passion while high sport valuation combined with an autonomous personality orientation would positively predict harmonious passion. A sample of 206 collegiate recreational athletes completed self-report questionnaires that assessed their level and type of passion as well as their personality orientation and sport valuation. The results of this study revealed that sport valuation and global personality motivation orientation played an independent, yet complementary, role in the way an activity becomes internalized in a person's identity. Specifically, sport valuation and an autonomous personality orientation positively predicted harmonious passion, whereas sport valuation combined with a controlled personality orientation positively predicted obsessive passion.

Vallerand and colleagues (Study 2, 2006) continued their investigation of passion and affective experiences with a sample of 210 competitive high school and junior college basketball players. The researchers believed that harmonious passion would predict positive affect and vitality experienced, while obsessive passion would be more negatively related, or unrelated, to 
positive affective variables. Vallerand et al. also believed that obsessive passion would be related to negative affect and harmonious passion would be negatively related, or unrelated, to negative affect. The participants were asked to complete questionnaires measuring passion, satisfaction with their sport, positive and negative affect in sport, vitality in sport and subjective well-being in sport. Researchers found that harmonious passion was positively and significantly related to all positive affective variables. The opposite pattern took place with respect to obsessive passion. Obsessive passion was significantly and positively related to negative affect. With regard to participants' perceptions of their well-being, harmonious passion was positively related to this variable while obsessive passion was not related to well-being at all.

Vallerand et al. (2006, study 3) continued their investigation on passion and affective experiences by conducting a longitudinal study to assess the determinants of passion and the outcomes associated with the two types of passion. It was hypothesized that harmonious passion would positively predict higher levels of subjective well-being, whereas obsessive passion would be negatively, or unrelated, to subjective well-being. The sample consisted of 107 water polo players and synchronized swimmers who took part in national competitions. The data collection consisted of two parts separated by four months. In the first data collection, athletes completed measures for passion, personality orientations and sport valuation. In the second data collection, athletes completed measures of satisfaction with sport, positive and negative affect and subjective well-being. As expected, activity valuation and an autonomous personality positively predicted harmonious passion, whereas activity valuation and a controlled personality predicted obsessive passion. Harmonious passion at phase 1 of data collection positively predicted subjective well-being in sport at phase 2 while obsessive passion at phase 1 was negatively related to subjective well-being to sport at phase 2 .

The role that passion plays in daily affective experiences is not limited only to the days in which the individual participates in that activity. This was shown in a study conducted by Mageau and Vallerand (2007). They hypothesized that, over a two-week period, the more harmonious passion individuals held for a given activity, the greater positive affect they would show on days when they engage in the activity. It was also hypothesized that individuals with high obsessive passion would experience a decrease in positive affect on days when they were not able to participate in their passionate activity. The sample consisted of 154 college students. On the first day of the study each participant was asked to complete measures for passion and 
situational affect. The study was longitudinal in nature so, on each day, participants were asked to keep a journal for 12 consecutive days. The participants were asked to describe their activity engagement and situational positive affect for each day. As expected, the journal entries showed that the more harmonious passion an individual held for an activity, the more they experienced high levels of positive affect on days they participated. However, a more surprising finding dealt with those individuals who had obsessive passion for the activity. Those individuals who had obsessive passion toward their activity experienced a greater decrease in positive affect on days they did not participate than an increase on days when they did participate in the activity. Mageau and Vallerand also observed that individuals who held obsessive passion for their activity participated in their activity less frequently and for less time once engaging in it. It is likely that individuals who hold an obsessive passion feel obligated to participate in the activity even if they do not have the requisite time. It is also possible that those individuals with harmonious passion have more volition regarding when they participate and will not engage in the activity unless they have sufficient time to fully devote to the activity. Those with obsessive passion feel obligated to participate and because of this participate in the activity regardless of how much time they have available and rush the activity. This may not give the individual sufficient time to become immersed but may help the individual experience less anxiety and guilt for not participating.

Again, the studies cited in the previous paragraphs indicated that the amount and type of passion that individuals hold toward their sport activity is related to, or predictive of, their affective experiences. In particular it appears that individuals who hold a harmonious passion for an activity experience more positive consequences than do those with obsessive passion. Another perspective on the passion construct as it may be exhibited in the sport context involves the assessment of the interactional effect between the person (type of passion he/she exhibits) and the nature of the sport environment. The research on this approach is reviewed in the next section.

\section{Person-environment fit}

According to the person-environment fit perspective, the type of passion an individual holds for an activity may benefit them in some situations but be a deficit in others. Passion and the person-environment fit hypothesis have been tested briefly but not extensively in the literature. A person-environment fit is achieved when there is a match between personal 
characteristics of the person and the characteristics of the environment. Thus, for example, an individual who is very competitive would encounter more happiness and success in a highly competitive environment than would someone who disfavors competition.

In line with the person-environment fit hypothesis, Amiot et al. (Amiot, Vallerand, \& Blanchard, 2006) hypothesized that highly competitive environments would be more suited to individuals with an obsessive passion. These environments promote a rigid and inflexible type of persistence and involvement and may result in an individual being excessively engaged which could result in deficiencies in other areas of life. Conversely, environments that are less competitive may be seen as a good match for those individuals with harmonious passion. A less competitive environment may require a lower investment of time and energy and may fit in with someone who has more diversified interests.

To investigate the person-environment fit, Amiot et al (2006) collected data in a Canadian hockey league. Participants were 233 male hockey players aged between 13 and 20 years $(\mathrm{M}=18$ years). All of the participants had been playing competitively in three of the most competitive non-professional hockey leagues of the Province of Quebec for a significant period of time and were attending a tryout camp for a competitive league. Those individuals who were not selected for the high competition league were placed in a lower level league. The higher competition league had more weekly on-ice-practices and on-ice hours, more off-ice training, more regular season games and greater average time traveling to away events. The league was rated by multiple experts as more demanding, more competitive and with higher intensity than the non-competitive league. All athletes completed questionnaires assessing their levels of passion at the initial tryout. Two weeks later, they filled out another questionnaire assessing psychological adjustment upon finding out if they had made the team. Finally, two months later, they filled out another psychological adjustment questionnaire after being allowed to acclimate to their surroundings.

The results of this study (Amiot et al., 2006) were quite consistent with the personenvironment fit. First, the athletes initially selected to the competitive team showed greater psychological adjustment than athletes who were not selected. Among athletes in the lower competition leagues, those with harmonious passion showed a higher psychological adjustment than those with obsessive passion. In high competition leagues, the exact opposite appeared. Those athletes with obsessive passion showed higher levels of psychological adjustment than 
those with harmonious passion. These results clearly suggest that it is not sufficient to know solely the passion type or the level of competition of an athlete to consider their psychological adjustment. Rather it was vital to know both the level of competition and the type of passion to maximize the psychological adjustment of the athletes. This is also significant, because under certain circumstances, it may not be debilitative to have obsessive passion as was previously believed. That is, it is possible that obsessive passion may help individuals in high pressure, high competition leagues more than will harmonious passion.

Sheard and Golby (2009) conducted an exploratory study to investigate whether harmonious and obsessive passion would be different for professional rugby players at different standards. British rugby is split into three main leagues: international, club and academy. In both international and academy, the level of competition for these positions is much more competitive than it is at the club level. Correspondingly, skill level is usually much higher in the international and academy leagues. The sample for the study consisted of 78 professional rugby players from varying standards: International $(n=33)$, Club $(n=25)$ and Academy $(n=20)$. Each participant was asked to complete questionnaires that assessed passion and positive and negative affect. The researchers found that among the rugby players, there were significant differences in obsessive passion between players in the three levels. In the more competitive international and academy levels, players had significantly higher obsessive passion than did those in the club level. Sheard and Golby speculate that the differences in obsessive passion are a result of the need by those athletes who continue to participate in the highly competitive and time consuming leagues to have a rigid (obsessive) persistence. In contrast, at the club level, athletes are more likely to pursue other activities because they are in a less competitive environment. Thus, harmonious passion may be a better option for them.

In general, then, the results of these studies do support the idea that there is a personenvironment fit. That is, individuals who hold a more obsessive type of passion may be more attracted to, and flourish in, more competitive leagues which do take up significant portions of individuals' lives and do not allow for other life pursuits. In contrast, individuals who hold a more harmonious type of passion may be more attracted to, or flourish better in a less competitive league. Another way to investigate the link between passion and athletes' well-being is to examine the more negative predictions inherent in the dualistic notion of passion. These studies are reviewed in the next section. 


\section{Passion and Negative Behaviors in Sport Contexts}

In the general passion literature (Vallerand et al., 2003; Vallerand \& Houlfort, 2003; and Vallerand \& Miquelon, 2007), passion has been associated with negative behaviors and less than ideal outcomes. Almost always these outcomes are due to individuals who hold obsessive passion for an activity. Some of the potential negative behaviors that might be associated with obsessive passion in the sport setting would include: rigid persistence in an activity under circumstances where injury risk is high and exhibition of high levels of aggression.

Vallerand et al. (Study 3, 2003) followed bicyclists to investigate the relationship between passion and task engagement during the summer and winter months. Some behaviors are beneficial but can turn detrimental if done incorrectly or at inopportune times. One of these activities is bicycling. In the summer, bicycling is a great way to enjoy the outdoors as well as get exercise. However, in the winter months, bicycling can be hazardous. The researchers believed obsessive passion may result in a rigid persistence in an activity, such as bicycling, and this rigid persistence may result in dangerous behavior during the winter months. The sample for the study consisted of 59 recreational cyclists. Each participant completed a measure for passion and were contacted in August and February and asked if they were cycling at the time. Vallerand et al. found that the athletes in the whole sample, during the summer, did not differ in their levels of harmonious passion or how committed they were to cycling. However, individuals who had higher levels of obsessive passion were more likely to engage in dangerous winter cycling. The only measured difference in those that engaged in risky behavior and those that did not was obsessive passion, which the researchers believed led the individuals to rigidly persist in their activity even when injury was much more likely.

Rip, Fortin and Vallerand (2006) investigated this relationship with dancers enrolled in a dance department at a prestigious university. In the professional dance environment, many individuals deal with injuries so frequently that they take injuries as a sign of vocational commitment. Some experts have suggested that individuals feel internally compelled to dance and perform even when they have injuries, because they come to be psychologically dependent on the physicality of their working lives. A hypothesized reason for this rigid persistence may be due to the passion held for dance, specifically obsessive passion for the activity. The researchers hypothesized that harmonious passion would be positively related to health-promoting activities while obsessive passion would be unrelated to, or even negatively related to health-promoting 
actives and positively related to less adaptive forms of coping. The sample consisted of 81 dancers in the Department of Dance at the University of Quebec at Montreal. The dancers had an average age of 22.1 and averaged 11.6 years of experience in dancing. The researchers had each participant complete measures for passion and injury information that included history of injury, prevention strategies, coping behaviors and response to pain and injury. The researchers found that passion did play an important part in injuries in dance students. Harmonious passion was negatively associated with prolonged suffering from acute injuries while obsessive passion was positively associated with prolonged suffering. Harmonious passion was also positively associated with healthy coping responses to injury, completely stopping dance activities when injured and engaging in self-initiated injury prevention regimes. Conversely, obsessive passion was associated with ignoring injury related pain, not stopping dance activities when injured, and failure to seek adequate treatment when injured. In general, then, harmonious passion was associated with healthy coping strategies and preventative injury behaviors while obsessive passion was associated with less healthy strategies, continuation of dance without treatment and suffering from an injury without reporting to a coach.

The role that passion plays in aggression has also been studied in the literature. Donahue et al. (Donahue, Rip, Vallerand, 2009) conducted two studies that investigated aggression levels in high school and college aged athletes. Aggression has been defined as one of two types; instrumental or reactive. Instrumental aggression involves causing a strategic nuisance to an opponent in order to hinder their performance. Reactive aggression is when frustration or anger is present, and the intent to harm another player is involved. The two studies conducted by Donahue et al are described in the following paragraphs.

Donahue et al. (Study 1, 2009) investigated the relationship of harmonious and obsessive passion and regular tendencies to display aggressive behaviors. It was hypothesized that athletes with obsessive passion would be more likely to display aggression than athletes with harmonious passion. The sample consisted of 208 high school and college basketball players. Each participant completed measures for passion and athletic aggression. Study results indicated that basketball players who had higher obsessive passion scores were more likely to display reactive aggression.

In an extension of the first study, Donahue et al. (Study 2, 2009) wanted to replicate the initial results from the first study as well as use hypothetical situations that either affirmed their 
identity or threatened their identity as an athlete. The researchers believed that obsessively passionate players would display more aggression than would harmonious passionate players in the identity threat situation. No differences between the harmonious and obsessive passion groups were expected in the self-affirmation group because their identity would not be threatened. The sample consisted of 60 high school basketball players attending a summer basketball camp. Each athlete filled out a measure assessing their passion for basketball and then were randomly assigned to either a self-affirmation manipulation or a self-threat condition. Following the manipulation, athletes were given three hypothetical basketball situations with conditions that highlighted the possibility of being an incompetent basketball player. The researchers found that individuals with obsessive passion scored higher on situational aggression and, in the manipulation, had significantly higher scores in the self-threat condition. As predicted, there were no differences in the self-affirmation group. Obsessive passionate individuals were also more likely to report aggressive behaviors in hypothetical situations than were harmoniously passionate participants. When the identity of athletes with obsessive passion was threatened, they displayed higher situational aggressive behaviors. This finding suggests that when experiencing a threat to their identity, obsessively passionate individuals will react aggressively to restore their threatened identity. One reason for this reaction could be that obsessive passionate individuals have their identity rooted in their sport, and when this identity is threatened, they react defensively and aggressively to protect their self-image.

In summary, the research studies described in the previous paragraphs suggest that athletes that hold an obsessive passion for their sport are more likely to suffer negative consequences than athletes who are harmoniously passionate. Another potential consequence of the obsessive form of passion might be higher levels of burnout in relation to the individual's activity. This link has not been examined in sport contexts but has been studied in work settings. This research is reviewed in the next section.

\section{Passion and Burnout}

Burnout is a syndrome that manifests itself in three distinct forms, emotional exhaustion, depersonalization and diminished personal accomplishment. Burnout typically results from cumulative stress experienced over prolonged, stress-laden periods. Burnout is a problem for individuals who are involved in high stress jobs. As a result, some of the people in these positions end up quitting while others who are exposed to the same level of job stress will 
continue. One possible explanation for these two differing outcomes could be the type of passion the individual holds for the work activity. The link between passion and burnout has been explored in the worksite by a couple sets of researchers. These studies are described below.

Carbonneau, Vallerand, Fernet and Guay (2008) conducted a study designed to investigate the relationship passion plays in the teaching environment. Previous research on teaching has debated the consequences of passion in teachers. One hypothesis of passion in teaching is that passion would be an antidote to teacher burnout, because those who are passionate are continually energized and reinvigorated by their work. A contrasting view of this hypothesis would be that those who are passionate about teaching may be at greater risk for burnout, because excessive passion leads people to engage in too much intensity in the teaching environment and might cause them to neglect other areas of life. To test these two conflicting hypotheses, Carbonneau and colleagues sent out survey packets at two time points (March and June) to individuals who were full time teachers. For the data analyses, only individuals who returned the surveys at both times were included, which resulted in a total sample of 494 teachers with backgrounds in elementary $(n=306)$, high school $(n=120)$, adult education $(n=20)$ or vocational and technical education $(n=46)$. The teachers were mailed packets that contained surveys that assessed their level of passion, work satisfaction, burnout and teacher-perceived student behavior. Carbonneau et al. used a correlation method to compare passion, work satisfaction, burnout and teacher perceptions of student behavior. The researchers found that of the teachers that were surveyed, $93.1 \%$ were at least moderately passionate. They also found that increases in harmonious passion from time 1 to time 2 predicted increases in work satisfaction and teacher-perceived adaptive student behaviors, as well as decreases in burnout over a 3-month period. In contrast, increases in obsessive passion from time 1 to time 2 were unrelated to job satisfaction and burnout. These findings support the idea that passion is more of an antecedent than a consequence of work satisfaction and burnout. In sum, the presence of passion alone was not sufficient in identifying the outcomes of teaching. Rather, the type of passion held by teachers was important in predicting teaching outcomes with harmonious passion leading to positive outcomes and obsessive passion being unrelated to positive outcomes.

Vallerand and his colleagues (Vallerand, Paquet, Philippe, \& Charest, 2010) hypothesized a model that would explain the relationship of burnout and passion in the work setting. In their hypothesized model, obsessive passion predicted conflict between work and 
other activities while harmonious passion was negatively predictive of conflict. Conflict was then expected to contribute to passion. Harmonious passion was expected to lead to satisfaction at work that in turn would be negatively correlated with burnout. In the model, conflict would be a contributing factor to burnout while work satisfaction would be a protective factor. The model was tested in two studies that are reviewed in the next paragraphs.

Vallerand et al. (Study 1, 2010) tested the proposed model on obsessive passion and burnout in a sample of 97 French nurses. It was hypothesized that obsessive passion would positively predict conflict between work and other life activities while harmonious passion would positively predict work satisfaction. Each participant completed measures for passion, work satisfaction, conflict and burnout. Study results were mostly consistent with the study hypotheses. Specifically, harmonious passion was positively correlated with satisfaction with work that, in turn, was negatively correlated with burnout. Obsessive passion was significantly and positively correlated with conflict, and conflict, in turn, was significantly predictive of burnout.

Preliminary results of the model provided some support, but Vallerand and colleagues wanted to extend their findings with a longitudinal study (Study 2, 2010). It was hypothesized that obsessive passion would lead to increases in conflict and burnout over a 6-month period and that harmonious passion would lead to increases in work satisfaction and decreases in burnout over the same time period. Only nurses who completed surveys at both time points were included in the final analysis. Thus, the final sample consisted of 258 Canadian nurses. Each participant completed an initial set of questionnaires that assessed passion, satisfaction at work, conflict and burnout. A second set of questionnaires was sent out six months after the initial testing and each participant completed the same measures. Study results indicated that obsessive passion indirectly led to burnout as mediated through a relationship with conflict between work and other characteristics and was unrelated to work satisfaction, a common inoculation for burnout. Harmonious passion was found to prevent burnout through a positive association with work satisfaction and a negative association with conflict. Not merely the presence of passion, but rather the type of passion that was present was important. Harmonious passion prevented the development of burnout whereas obsessive passion promoted burnout. In discussing these results, Vallerand et al. compared passion to a double-edged sword where "On the one hand, one type of passion (obsessive) is conducive to burnout, whereas on the other hand, the other type of 
passion (harmonious) prevents its occurrence. Thus an important issue, with respect to burnout, is not whether someone is passionate or not toward work but rather whether someone displays a harmonious or an obsessive passion (p. 309).“

As noted previously, there currently is no research to examine the potential relationship between passion and burnout in the sport setting. Thus, a primary aim of the current study was to examine this link between passion in young athletes and their levels of sport burnout. In addition, a second focus of this study was to examine the possible relationship between athletic identity and burnout levels. This component was included as a second predictor of burnout in the current study because the model of passion proposed by Vallerand and his colleagues (Vallerand et al., 2003; Vallerand \& Houlfort, 2004; Vallerand and Miquelon, 2007) suggests that for an activity to become a passion in individuals' lives, it has to maintain a significant place within their sense of themselves. As Vallerand (2008) describes it, when individuals develop a sense of passion for an activity, that activity becomes a central portion of their identity. Within the sport literature, the construct of athletic identity has been defined and examined relative to a number of other psychological and behavioral variables. However, no previous research has examined the possibility that both athletic identity and passion may combine to affect levels of burnout in adolescent athletes. To provide a basis for the inclusion of athletic identity as a predictor of burnout, the research and theory related to athletic identity is summarized in the next section.

\footnotetext{
Athletic Identity

The literature has supported the idea that individuals do not assess their self-concept in a unidimensional manner. Rather, they take a multidimensional approach (Harter, 1990; Markus $\&$ Wurf, 1987). Therefore, instead of making global assessments of themselves, individuals tend to use domain specific judgments of self-worth and competence. For example, if an individual is not competent in math or science, normally, they do not judge themselves as being incompetent in all aspects in life. Rather they judge themselves as being incompetent in the subject in which they are struggling. Similarly, if an individual is succeeding in the work realm, they understand that that success does not automatically transfer to other aspects of their lives. The level of importance attributed to a self-concept domain will determine the extent to which perceived competence or incompetence in that area will affect an individual's motivation, selfesteem and affect (Brewer, 1993). When an individual places low importance in a domain,
} 
success or failure will have relatively low impact on their motivation, self-esteem and affect. Conversely, if an individual places a large amount of importance in a domain, the perceived incompetence may have large effects on the individual's feelings of self-worth. Many individuals report a great deal of psychological significance from their involvement in sport and exercise (Eldridge, 1983). Because of the significance individuals place on the athletic realm, many individuals identify strongly with the athlete role, but the importance of the athletic role varies between individuals. To better understand the athletic role, Brewer, Van Raalte and Linder (1993) defined athletic identity as "the degree to which an individual identifies with the athlete role (p. 237)." An individual with high athletic identity places great importance on their success or failure in the athletic realm and may attribute large portions of their self-worth to these accomplishments. These attributions may lead to negative consequences to individuals, especially if they place excessive emphasis of success in only one realm.

Athletic identity was first conceptualized as a social role (Pearlin, 1983). By considering athletic identity as a social role, it acknowledges the importance of others in shaping this identity. The extent to which an individual labels her/himself as an athlete is strongly influenced by individuals within the athlete's social environment who give that athlete reinforcement. These social agents include parents, coaches, teachers, and peers (Heyman, 1986). If individuals are constantly being applauded by parents, coaches, and peers for their play in sports, and the athletes perceive that these social agents place importance on the athlete role, then such athletes are much more likely to develop a stronger sense of being an athlete. In adolescence, the formation of athletic identity may also be influenced by peer groups, because at this time, athletes begin to value the opinions of their peers more than from parents and other older rolemodels (Harris, 1995).

\section{Measurement of Athletic Identity}

Even though athletic identity had been theorized in the literature, no dependable measurement was developed and tested until Brewer and colleagues (1993) created the Athletic Identity Measurement Scale (Brewer et al., 1993) and tested its validity through a series of studies. In the first study (Study 1), the AIMS was compared to the Perceived Importance Profile (Fox, 1987) and the Marlowe-Crowne Social Desirability Scale (Crowne \& Marlowe, 1960) in collegiate students. Mean scores on the AIMS increased with the level of athletic involvement of the participants. The scores on the AIMS were highly correlated with scores on 
the Perceived Importance Profile sports competence scale, and none of the AIMS item scores was significantly correlated with scores on the Marlowe-Crowne Social Desirability Scale. Brewer and colleagues (Study 2, 1993) further extended the validity of the AIMS and compared the AIMS to the Self-Role Scale (Curry \& Weiss, 1989), the Sport Orientation Questionnaire (Gill \& Deeter, 1988) and a measure for self-esteem. The researchers found that even though the AIMS and the Self-Role Scale shared some variance, they did not share significant amounts, thus leading Brewer et al. to conclude that the two scales did not measure the same underlying construct. The individuals who scored high on the AIMS were likely to have higher sport-related competitiveness, goal orientation and win orientation than did those who scored low on the AIMS. The Rosenberg Self-Esteem Scale and the AIMS were not significantly related to each other thus suggesting that the two constructs are independent. In a final study, Brewer and colleagues investigated the relationship between athletic identity (AIMS), the Physical SelfPerception Profile, (Fox and Corbin, 1989) and the Perceived Importance Profile (Fox, 1987). The only significant correlation found was between the AIMS score and one subscale of the Perceived Importance Profile, specifically the PIP-Sport. The PIP-Sport relates to the importance of sport competence to an individual. When the level of involvement is held constant, athletic identity is related to the importance one places on being competent in the sport. Although these constructs are related, they are independent and unique. The non-significance of the other scales to the AIMS demonstrates that athletic identity is different from physical selfesteem, perceived importance of fitness, body attractiveness and strength, and coach rated football ability. Brewer et al. found that as college students mature and become exposed to a variety of activities, the athlete role decreases in importance, and they become more multidimensional rather than relying on their athletic exclusivity. The AIMS, as conceptualized and tested by Brewer and colleagues, appeared, then, to be a trait-like construct that is unidimensional.

In subsequent studies, however, the unidimensional nature of the AIMS (Brewer et al., 1993) began to be questioned. That is, even though initial exploratory factor analysis revealed the AIMS to be unidimensional (Brewer et al., 1993), other studies suggested that it was more accurately depicted as a multidimensional scale (Brewer, 1990; Brewer, Boin \& Petitpas, 1993). Specifically, Brewer (1990) and Brewer, Boin \& Petitpas (1993) found the AIMS to contain three distinct dimensions labeled "social identity," "exclusivity," and "negative affectivity." 
Social identity is the strength with which athletes identify with the athlete role. Exclusivity is the degree to which athletes rely solely on their athletic identity and identify less strongly with other roles. Some of the roles that may be less identified include worker, student, friend, brother or sister. Negative affectivity measures negative emotional responses to not being able to train or compete as an athlete due to injury, retirement or other reasons (Brewer, 1993; Brewer et al., 1993).

Martin, Mushett, Smith and Eklund $(1994,1995,1997)$ conducted a series of investigations with adolescent athletes with disabilities to determine the validity of using the AIMS with a special population. The AIMS seemed to fit well with the athletes with disabilities. However during the course of the studies, a fourth dimension (self-identity) consistently emerged. Martin et al. (1994) have suggested that social identity and self-identity are different constructs, because self-identity relates to the athletes' views of themselves as athletes, whereas social identity was the athletes' perceptions of others' views of them as athletes. The results from the three studies by Martin and colleagues were all conducted with small sample sizes that could have resulted in the additional subscale.

More research on the dimensionality of the AIMS was conducted by Hale and colleagues (Hale, James, \& Stambulova, 1999). Much of the previous work done to validate the AIMS was done with American university students. Thus, Hale et al. thought it was necessary to use a multicultural sample to examine the dimensionality of the AIMS in order for it to become a useful and valid measure in sports psychology. A sample consisting of American Division I athletes, United Kingdom national team athletes, and Russian physical education students at a Russian University were used in the study. The researchers compared the originally proposed unidimensional model, along with the three and four-dimension models to find best fit among the multi-cultural sample. The results from the study showed that the unidimensional model had the poorest fit among all three cultural groups. The AIMS model with three dimensions, social identity, exclusivity, and negative affectivity had the best fit within all three samples. The contrast between the three dimensional model and the four-dimension model hypothesized by Martin and colleagues $(1994,1995,1997)$ was explained by Hale and colleagues (1999) as due to the small sample sizes in the Martin studies. Hale et al. found no rationale or justification for the fourth AIMS factor from their analysis and extended the rationale for a three dimension AIMS with social identity, exclusivity and negative affectivity. 
To further solidify the dimensionality of the AIMS, Brewer and Cornelius (2001) used a large, diverse sample to finalize the dimensionality of the AIMS and to generate norms for future researchers. Previous research on the dimensionality of the AIMS had been hampered by the use of small same sport samples or samples with specific characteristics. The sample Brewer and Cornelius used was 2,856 participants from varsity, non-athlete and medicine clinic patients. The group had NCAA Division I, II, and II participants and involved 20 different sports. From their confirmatory factor analysis, three items were eliminated from the original 10-item scale due to poor performance in the factor analysis. From the new 7-item scale of the AIMS, norms for male and female athletes were given with males $(\mathrm{M}=35.92)$ holding a significantly higher athletic identity than females $(M=30.15)$. As expected, athletes scored significantly higher on the AIMS than non-athletes. The current form of the AIMS is now the 7-item, 3-dimension measure that Brewer and Cornelius proposed.

Even though the AIMS (Brewer, Van Raalte, \& Linder, 1993) is the most used measure in the sports psychology field, it is not the only measure for athletic identity. Anderson (2004) developed the Athletic Identity Questionnaire in response to "the existing measures of identity presented as one-factor scales (p. 40)." Anderson also believed that "no scale captured the broad conception of athletic identity that includes multiple social roles; includes exercise, sports and physical activity; is amenable to change despite its relative stability; is a social product, defined and maintained within the context of social relationships; and reflects prominence within an individual's identity salience hierarchy (p. 41-42)." The researcher hoped to develop a multidimensional construct with five dimensions that encompassed how the self evaluates information about its physical appearance, its competence, its level of commitment and importance of exercise, its effort to confirm itself as athletic through environmental choices, and its level of support the individual receives from others. Anderson conducted two studies with a university population. Each group completed the Athletic Identity Questionnaire, their stage of exercise behavior, and their exercise frequency. Anderson found support for a first-order, fourfactor model and the use of four domain specific scores in contrast to one overall score as assessed by other athletic identity measures. Multiple facets emerged from the analysis of selfknowledge including knowing oneself is athletic, athletic appearance, importance of sport activity to an individual, competence to perform these activities, and encouragement from others. Of the four dimensions, all weigh equally on an athlete's identity with no one more important 
than the other. Anderson's Athletic Identity Questionnaire (2004) was shown to demonstrate initial validity for the athletic identity construct, however Brewer's Athletic Identity Measurement Scale (1993) has demonstrated more extensive validity and will be the measurement of choice in the proposed study.

Over the past couple of decades, a relatively large number of studies have been conducted to examine the relationship between athletic identity and other psychological and behavioral constructs. The relevant studies from this body of research are reviewed in the next section.

\section{Athletic Identity: Correlates and Consequences}

One area that has been examined relative to athletic identity is the sport retirement process. Specifically, it was considered possible that retiring athletes may be confronted with issues with their self-concept. Before retirement, athletes attributed large portions of their identity to their sport. Following cessation of sport, they may encounter difficulties adjusting to life without sport participation. Not only must they adjust to the loss of a sport, but high level athletes also must adjust to the loss of their main social support. Athletes spend large amounts of time with teammates or training partners, and retirement may make interacting with these individuals more difficult. The loss of identity and the loss of social support are two major obstacles athletes must face when retiring from sport.

To investigate the major obstacles that retiring athletes might face, Lavallee, Gordon and Grove (1997) used qualitative methods with 15 athletes who had been identified as having experienced highly distressful reactions to retirement from sport. The athletes completed an autobiographical record as well as filling out the AIMS. The athletes were asked to report specifically on the following issues: degree of adjustment necessitated by retirement; whether or not they had confided in others about their adjustment; in who they had confided; the reactions of the confidants to their accounts; what effect the confiding had on the overall adjustment; and present feelings about their retirement experiences. Lavallee and colleagues analyzed the data and found that reporting emotions and feelings was beneficial and that confiding with others may assist athletes who have experienced difficulties in career termination. The individuals with high athletic identity at the time of their retirement experienced a higher degree of emotional adjustment difficulties. When individuals become highly involved in their sport, they may develop a stronger athletic identity. This rather intense level of identification with being an 
athlete may limit their ability to develop a more differentiated self-concept that includes other activities and roles.

Grove, Lavallee, and Gordon (1997) further examined the relationship between sport-role identification and the quality of adjustment to retirement in athletes while also assessing how athletic identity was related to coping strategies utilized during the career termination process. The sample consisted of 48 retired Australian national or state team athletes. Researchers gave participants the AIMS and COPE inventory (Carver, Scheier \& Weintraub, 1989) and assessed the quality of their adaptation to retirement by asking each athlete to rate the degree of occupational, financial, emotional and social adjustment necessitated from their retirement on a 10-point Likert scale with $1=$ No adjustment and $10=$ Considerable Adjustment. The self-report scales of emotional and social adjustment had strong positive correlations with athletic identity at time of retirement. AIMS scores also were positively related to anxiety about career decisionmaking after retirement and negatively correlated to the amount of pre-retirement planning. The extreme AIMS groups differed in the way they coped with retirement. High athletic identity was positively related to venting emotions, mental disengagement, behavioral disengagement and reliance on denial. The prolonged use of these strategies may interfere with more productive problem-focused strategies. The individuals with strong and exclusive athletic identity were found to have increased transition difficulty and relied more on denial following retirement.

To further investigate the role athletic identity has on the sports career termination, Cecić Erpič, Wylleman, and Zupančič (2004) collected data from 85 Slovene semi-professional athletes who had been retired more than 1 year but less than 4 years. Athletes were given questionnaires that assessed selected aspects of the sports career termination process. This included characteristics of active sports career, termination, transition to post-sports life, and adaptation of post-sports life. The researchers found that athletic identity had a significant effect on the degree of difficulties experienced by the athletes in the sport termination process. Specifically, participants who had high athletic identity perceived more difficulties than did those individuals who had lower athletic identity. Strong identification with the athlete role was related to more severe and frequent psychological difficulties as well as more difficulties in their post-sports lives.

In summary, then, the studies conducted with retiring or retired athletes have shown that individuals with high athletic identity may experience more difficulties with disengagement from 
their sporting careers. The degree of one's athletic identity may restrict growth in other life aspects and create more difficult transitions out of sport. Other studies have been conducted to examine the effects that athletic identity may have on individuals who experience career threatening or career ending injuries. These studies are reviewed in the following paragraphs.

Brewer (1993) conducted a series of studies to investigate the relationship between athletic identity and injury. Brewer (Study 1, 1993) first used athletic identity to predict a depressive response to a hypothetical career-ending injury. He hypothesized that individuals with higher athletic identity would have higher depression scores followingg the hypothetical injury. The sample consisted of 109 undergraduate students enrolled in a sports psychology class. All students filled out the AIMS (Brewer et al., 1993) and POMS (McNair, Lorr, \& Dreoppleman, 1971). The students were split into a control group and a manipulation group. The manipulation group completed the AIMS and then was read an imagery script and told to imagine suffering a career ending injury. Following the imagery they completed the POMS. The control group was not read a script but still completed the AIMS and POMS. Within the groups that imagined they had experienced a sport injury, those who had higher athletic identity showed higher depression.

Brewer (Study 2, 1993) wanted to replicate previous findings and again assessed the relationship of athletic identity and mood states following a traumatic experience. The sample consisted of 131 students enrolled in a social psychology class. The sample was given the AIMS (Brewer et al., 1993) and POMS (McNair, Lorr, \& Dreoppleman, 1971). The sample was randomly assigned to an injury or course failure condition. The injury group was told to imagine a career-ending injury while the course failure group was told to imagine that they were to fail a course that prevented them from majoring in a preferred field of study. Participants were told to complete the AIMS, given the manipulation and then completed the POMS. Those individuals who were in the course failure group had higher depression scores than the individuals in the injury situation, likely because all participants were students while only some participants were athletes. The study showed that, similar to study 1, individuals with higher athletic identity had higher depression scores following a hypothetical injury than did individuals with lower athletic identity.

In a third study, Brewer (1993) looked at the depressive mood of athletes who had actually experienced an injury. The sample consisted of 121 injured athletes. The participating 
physician rated the extent of the participants' injuries on a 3 point scale $(1=$ mild, $2=$ moderate, $3=$ severe). Participants were given questionnaires to assess athletic identity, physical selfefficacy, depression and a sport-specific measure of stressful life events. The results verified, again, that athletic identity was positively related to depression in injured athletes.

Finally Brewer wanted to compare the relationship of athletic identity and depression in injured athletes and non-injured athletes (Study 4, 1993). The sample consisted of 90 members of the University of California, Davis varsity football team. The athletes were all given a battery of questionnaires that assessed athletic identity, physical self-efficacy, depression and a sportspecific measure of stressful life events prior to the first game. The athletes were also asked about their current health status. With these responses, 15 athletes were placed in the injured group and 75 were placed in the uninjured group. The main predictor of depression in the sample was an interaction between injury status and AIMS scoring. Athletic identity was positively related to depression in injured athletes and negatively related to depression in uninjured athletes. In general, the series of studies conducted by Brewer showed that athletic identity played an important role in depression in injured athletes with athletes who had higher athletic identity having higher depression scores when faced with injury.

Manuel et al.'s study (Manuel, Shilt, Curl, Smith, DuRant, Lester, \& Sinal, 2002) investigated the relationship between significant injuries and athletic identity. The sample contained 48 teenage athletes who had been injured in sport. Each participant completed surveys for depression, athletic identity and coping mechanisms for the injury. The researchers found that, after accounting for injury severity, high athletic identity was associated with early depressive symptoms.

As the studies described in the previous paragraphs show, athletic identity is a primary factor in determining how athletes react to sport injuries. Other studies have been conducted to examine links between athletic identity, sport orientation, anxiety, and college adjustment. These studies are reviewed in the following paragraphs.

Daniels, Sincharoren and Leaper (2005) looked at the relationship between athletic identity and sport orientation in an adolescent population. They believed that sport orientation may mediate the relation between sport participation and athletic identity among adolescents. The sample consisted of 169 adolescents with an average age of 13.8 and who played a variety of sports including tennis, swimming, basketball and water polo. Each athlete was asked to 
complete the AIMS (Brewer et al., 1993) and the Sport Orientation Questionnaire (Gill \& Deeter, 1988). The results of the study showed that boys scored significantly higher than did girls on competitive and win orientation, but no gender differences were found for goal orientation. Goal orientation was found to significantly mediate the relationship between sport participation and athletic identity in boys while win orientation was found to mediate the relationship of athletic identity and sport participation in girls. These findings suggest that adolescent boys and girls may construct their identities differently in athletics. For boys, viewing oneself as an athlete depended on holding a goal orientation while for girls, viewing oneself as an athlete was related to having a win orientation.

Athletic identity has also been examined in relation to sport anxiety. Masten and colleagues (Masten, Tušak, \& Faganel, 2006) administered surveys to 410 Slovene athletes from various competition levels to measure their athletic identity (AIMS) and their levels of trait and state anxiety (STAI-X1 STAI-X2: Spielberger, Gorsuch, \& Lushene, 1970). The researchers found athletes who were classified as "World Class" had higher levels of both state and trait anxiety than did athletes who were classified in the lower divisions of sport. Masten and colleagues also found that an increased self-identity corresponded with a decrease in an athlete's state and trait anxiety while an increase in negative affectivity had the opposite effect on anxiety in the sample of athletes. The research found that men were less anxious than women in both trait and state anxiety.

Melendez (2010) investigated the importance of athletic identity in the college adjustment of Division I student athletes. The sample consisted of 101 athletes competing at three Division I programs. The participants were asked to complete the AIMS along with a survey to assess college adjustment. Melendez found that males, as well as Caucasian athletes, had higher scores on the AIMS than did females and African-American athletes. Caucasian athletes may have had higher scores, because the athlete role may have been less salient than other identities for African-American athletes. Academic adjustment and personal-emotional adjustment were both inversely related to athletic identity in the sample. In addition, higher athletic identity scores were associated with lower academic adjustment scores among the Caucasian student athlete group.

Athletic identity was also studied in relation to career maturity and identity foreclosure in collegiate athletes. Specifically, Murphy, Petitpas and Brewer (1996) wanted to assess the extent 
to which student athletes' level of athletic identity and identity foreclosure related to career maturity and examine the differences in these variables as a function of gender, playing status (varsity vs. non-varsity), and sport (revenue vs. non-revenue). A sample of 128 NCAA Division I athletes were given the AIMS, the Foreclosure subscale of the Objective Measure of EgoIdentity Status (Adams, Shea, \& Fitch, 1979), and the Attitude scale of the Career Maturity Inventory (Crites, 1978). Murphy and colleagues found that women had significantly higher career maturity scores than men, but males and females did not differ on identity foreclosure or athletic identity. Varsity athletes had significantly higher identity foreclosure and athletic identity and lower career maturity than did non-varsity athletes. Those athletes in revenue producing sports had significantly higher foreclosure scores and lower career maturity scores than did those in non-revenue sports. The researchers concluded that male varsity athletes in revenue producing sports may be at a particularly high risk for restricted career maturity and other negatives associated with high athletic identity.

In general, the results of the studies described in the previous paragraphs indicate that athletic identity is associated with a number of other psychological variables. Other research has been conducted to identify how athletic identity is developed within athletes. These studies are reviewed in the next section.

\section{Development of Athletic Identity}

Grove, Fish, and Eklund (2004) wanted to investigate the role of team selection in the development of athletic identity. The sample consisted of 48 high school female athletes participating in tryouts for state all-star teams. Athletes were recruited from the highest level of amateur competition in a major metropolitan area of Western Australia and participated in volleyball, basketball or field hockey. The researchers wanted to see the effect that team selection and non-team selection would have on the athletes' levels of athletic identity. The AIMS was given to athletes at a tryout prior to announcement of team selection, the same day as team selections, shortly after players were informed of selections, and 2 weeks following team selection. The AIMS scores for the athletes did not significantly differ at the first testing. For those athletes who were selected to the teams, the athletic identity scores did not change. However, those participants who were not selected exhibit a decrease in athletic identity from before they were "cut" to after. As a result, their after scores on athletic identity were lower than those from athletes who were selected to the team. Thus, it appears that whether or not athletes 
are selected to competitive teams (following tryouts) does have some effect on their sense of themselves as athletes.

Houle, Brewer and Kluck (2010) investigated the developmental trends of athletic identity in a retrospective manner with collegiate participants. In the first study, 63 female collegiate gymnasts were asked to complete an AIMS for their current age and then also retrospectively fill out the AIMS for when they were age 10 and 15. The gymnasts reported significantly lower athletic identity at 10 years of age as compared to the same construct at age 15 and at their current age. Furthermore, significant differences were found in athletic identity scores from age 15 to their current age. In the second study, 179 collegiate students were asked to complete the same retrospective process. The sample consisted of athletes in collegiate sports $(n=33)$, those not currently involved in sport but participants in high school $(n=112)$, and individuals who had never participated in a sport $(n=34)$. For those individuals still involved in a sport, similar results to the gymnasts were found. They had significantly higher levels of athletic identity for their current age and at age 15 as compared to their scores at the age of 10 . The current athletes also showed significantly higher current athletic identity than either the former athletes or the non-participators. As expected, the group of non-athletes had significantly lower athletic identity at both age 10 and 15 than did the current and former athletes. There were no significant differences in athletic identity levels of current to former athletes at either the age 10 or 15 . These results indicate that athletic identity is mostly constant for athletes over the age of 15 as long as they are still involved competitively in their sport. However, following retirement, athletic identity can significantly decrease.

The determinants of athletic identity had not been previously investigated in the literature until Stephan and Brewer (2007) conducted in-depth, open-ended, semi-structured interviews with 10 Olympic athletes following their retirement after the Olympic Games. Athletes were involved in a variety of sport including canoe, wrestling, archery, fencing, rowing and synchronized swimming. The initial point of the interviews was to evaluate the degree to which these athletes defined and considered themselves athletes during their sporting career. All of the athletes emphasized that in order to stay focused on sport-related goals they needed to concentrate on their role and status as athletes. Multiple factors emerged from the data concerning their identification of themselves as athletes. These factors, identified by the researchers from the data, included social factors and personal factors. Multiple sub-factors 
emerged from these two factors with socio-professional flexibility, sports staff, peers and teammates and social recognition emerging from the social dimension. Self-identification with the elite sport lifestyle and bodily dimension of sport emerged from the personal factor dimension. Socio-professional flexibility was the freedom of the athlete in their secondary profession that signaled a decrease of importance in this new job and an increase to the athlete role. The coaches and support staff gave the athletes reinforcement that reaffirmed the athletes' beliefs of being an elite athlete. The contact with peers and teammates aided in their development of athletic identity by helping them remain focused on their sport by being surrounded by like-minded individuals, giving a feeling of being immersed into the sport world and feeling like a member of an elite sport group. The social recognition helped athletes see themselves as athletes in the media. The self-identification with the elite sports lifestyle was a life organized around training, travel, and competition. The bodily dimension of sport was when the athletes realized they did not have the body of an average individual, rather they perceived that their bodies were unique. Overall, the researchers found that the determinants of athletic identity were multidimensional with both social and personal influences. Athletes feel as if they are unique and exceptional people, and this feeling of importance is reinforced by coaches, peers, and others.

As previously mentioned, Brewer (1993) demonstrated that the strength of athletic identity to an individual's overall self-concept varies with past experiences and relative successes within the athletic domain. However, many individuals have high levels of athletic identity and never experience negative consequences. With this in mind, Horton and Mack (2000) investigated if athletic identity led to dysfunctional commitment or functional focus in a group of adult marathon runners. To train for and complete a marathon takes large amounts of personal commitment and may lead these athletes to neglect other life roles. The goal of the study was to assess the relative importance of running to marathon runners and examine the relationship between athletic identity and social networks, feelings of social isolation, sleep disturbance, illness, body image, self-confidence and anxiety levels. The sample consisted of 236 adults (aged 19 -72) who had been active in running for an average of 11.2 years. Participants were given a questionnaire that assessed athletic identity, life roles and the centrality of each role in the participant's life, positive and negative effects of marathon training and sport commitment. For analysis, participants who scored below the $33^{\text {rd }}$ percentile on the AIMS were classified as 
low athletic identity individuals, and those scoring above the $67^{\text {th }}$ percentile on the AIMS were classified as having high athletic identity. As the level of athletic identity increased, involvement opportunities in running and perceived social constraints to continue running also increased. The researchers found no significant differences in relative importance ratings to other life roles which indicate that a strong athletic identity does not preclude the development of a multidimensional self-concept. High levels of athletic identity were associated with greater experiences of positive psychological consequences of training such as enhanced body image, increased self-confidence, and decreased anxiety. It was also associated with greater enjoyment of running and greater overall commitment to running. Collegiate and adult runners exhibited relatively similar levels of athletic identity, however, running represented a larger part of the overall self-concept for collegiate athletes. Collegiate runners had a less complex self-concept, as they were found to have fewer categories to define their self-concept and were more reliant on their role as an athlete. Horton and Mack also found that a strong athletic identity benefited athletic performance and led to positive psychological experiences and physical performance. Athletic identity was found to benefit runners, but there is a risk for younger athletes with a less complex self-concept. Individuals who rely too much on their athlete role may experience pressure to continue participation which may lead to a greater number of negative consequences than adults who have more to draw their self-concept from than just the athletic role.

\section{Athletic Identity and Burnout}

In an early study conducted with junior tennis players, Gould et al. (1996) compared athletes who had been identified as burned out with non-burnout athletes and found no differences in their levels of athletic identity. In contrast, Raedeke (1997) found that adolescent swimmers who had the highest levels of burnout exhibited lower swimming identity scores than did the other swimmers in his study. To investigate these two contrasting viewpoints, Black and Smith (2007) conducted a study to examine the relationship between athletic identity and burnout in adolescent swimmers. The sample consisted of 182 senior level swimmers with an age range of 13-22 ( $\mathrm{M}=16.0)$ Black and Smith predicted that individuals with greater athletic identity exclusivity and lower perceived control would have higher burnout perceptions over and above the traditional stress based variables, and relatively high stress in combination with these variables would further predict burnout. The researchers administered self-report questionnaires to measure swimmers' levels of athletic identity, perceived swimming competence, perceived 
choice and burnout. The results showed that the athletes had low to moderate scores on all burnout dimensions. In addition, the swimmers, on average, reported low to moderate stress, moderate day-to-day control, participation control, moderate to high levels of athletic identity exclusivity and strength. However, the researchers found that higher perceived stress, lower participation control and higher weekly yardage were associated with higher emotional exhaustion. Higher perceptions of reduced accomplishment correlated with higher perceived stress as well as lower swimming competence, weekly yardage, identity strength, identity exclusivity, participation control and day-to-day control. Higher devaluation was associated with higher perceived stress as well as lower identity strength and exclusivity, participation control and day-to-day control. Regression analyses were conducted and showed that higher perceived stress and higher weekly yardage were predictive of higher emotional exhaustion scores while participation control inversely predicted exhaustion. Lower competence scores, higher perceived stress and lower identity exclusivity were associated with higher scores on reduced accomplishment. Higher perceived stress, lower athletic identity exclusivity and lower perceived participation control predicted higher scores on the devaluation burnout dimension. Overall, the researchers found that participation control contributed to the prediction of exhaustion and devaluation, and identity exclusivity contributed to the prediction of reduced accomplishment and devaluation. Higher exhaustion scores resulted when relatively high exclusivity was combined with relatively low control perceptions by the athletes. The highest levels of emotional exhaustion were demonstrated when relatively low exclusivity was combined with relatively low participation control and high day-to-day control. Overall, it appeared that participation control is more salient to burnout than day-to-day control. That is, day-to-day control failed to predict any of the burnout dimensions. If an athlete does not have control over participating in the first place, the day-to-day control within the setting may not be salient to an athlete. The direction of exclusivity was opposite the hypothesis of the researchers. Athletes with more exclusive identities reported lower levels of reduced personal accomplishment and devaluation. The findings of Black and Smith about athletic identity are consistent with Raedeke's (1997) earlier observations that young swimmers with relatively higher burnout perceptions have relatively lower athletic identity. It further supports the idea that a strong athletic identity may inoculate an athlete from the symptoms of burnout. It also demonstrates 
that individuals who do not have this strong athletic identity may be at risk for burnout and the consequences associated with it.

In summary, then, the research that has been conducted to examine the link between athletic identity and burnout levels has led to some mixed results. Thus, it seems necessary to include athletic identity, as well as passion, as possible predictors of burnout levels in young athletes. To provide a framework for examining burnout in young athletes, this topic is reviewed in the following section. Because the current study focuses on athletes in the adolescent age period, the research studies that are examined in the next section are those that predominantly included athletes in that particular age group.

\section{Burnout in Sport Settings}

In the sport environment, burnout has been defined "as a psychological, emotional, and physical withdrawal from a formerly pursued and enjoyable sport as a result of excessive stress which acts on the athlete over time" (Smith, 1986, p. 37). In the workplace setting, the burnout syndrome has been characterized in by three distinct dimensions: emotional exhaustion, depersonalization and low feelings of accomplishment (Maslach \& Jackson, 1981). Due, however, to the contextual differences between the working environment and the sporting environment, Raedeke (1997) modified these three dimensions to include: physical/emotional exhaustion, sport devaluation and a reduced sense of accomplishment. Physical/emotional exhaustion is associated with intense training and competition. An individual experiencing emotional exhaustion would dread doing an activity that previously was enjoyed, feel as if he was going through the motions or feel emotionally exhausted after the activity when previously he felt little to no exhaustion. A reduced sense of accomplishment is related to skills and abilities. Decreased feelings of accomplishments materialize as feeling that efforts are wasted or worthless and an overall feeling of frustration. Sport devaluation refers to a loss of interest or resentment toward the sport and performance results. An individual suffering from high feelings of sport devaluation would become apathetic about his sport and not care about personal or team performance. The dimensions of physical/emotional exhaustion and a reduced sense of accomplishment are similar to the constructs in the work environment, however, the devaluation dimension in sports is different than the depersonalization dimension in the work environment. The Raedeke dimension of sport devaluation focuses more on the value an individual places on 
their performance and on sport in general rather than the interpersonal relationships like depersonalization does in the workplace.

\section{Theoretical Models of Burnout}

To better understand the process that individuals experience when suffering from burnout, it is important to consider previous conceptual models. Multiple models have been hypothesized in sport's burnout including Smith's Cognitive Affective Model (1986), Coakley's unidimensional identity (1992), Silva's negative training stress model (1990), and motivational models that include Deci and Ryan's self-determination theory (1985) and Raedeke's (1997) entrapment view. These conceptual models will be discussed briefly.

The first model to investigate burnout in the sports realm was Smith's CognitiveAffective Model (1986). Smith developed a stress-based model of burnout that showed burnout as a process that proceeds in a predictable manner. Smith believed that if the demands of a situation are greater than the available resources, a typical response is an increase in stress for the individual, which in turn influences motivation and personality factors. This increase in stress may result in burnout for an individual.

Unlike Smith's stress-based model (1986), Coakley's unidimensional identity theory (1992) posits that "burnout is a social problem rooted in the social organization of high performance sport itself (p. 272)." In interviews with individuals who had burned out of their sport, Coakley found that a common theme among the athletes was that burnout resulted from a condensed set of life experiences leading to a unidimensional identity and a loss of control in their life from a combination of factors including the actions of coaches, parents and themselves. While initially they chose their sport, as they approached their goals, they felt less and less control over the choices impacting their lives. Coakley believed that burnout was more related to powerlessness than the personal flaws that had been hypothesized in a stress based model.

Silva's negative training stress model (1990) hypothesized that burnout was caused when training volumes are too high and too intense. Further research by Kentta and colleagues (Kentta \& Hassmaen, 1998; Kentta, Hassmen \& Raglin, 2001) has shown that physical training is a component in the burnout process. However, burnout is not just a matter of physical overtraining (Gould \& Whitley, 2009). The burnout process contains psychological and social components and to only assume training as a causal factor would leave an incomplete picture. 
Deci and Ryan's self-determination theory (1985) has also been used as a conceptual framework for burnout. Perrault and colleagues (Perrault, Gaudreau, Lapointe, \& Lacroix, 2007) hypothesized that if the three components of self-determination theory, autonomy, competence and relatedness, were fulfilled, then athletes would demonstrate lower burnout ratings. They found that satisfaction of each of the three basic needs was correlated with athlete burnout, and all three components of burnout were significantly predicted by the satisfaction of the need for autonomy. Similar results have been found in respect to elite rugby players and collegiate swimmers (Cresswell \& Eklund, 2005; Hodge, Lonsdale \& Ng, 2008; Lemyre, Treasure, \& Roberts, 2006). Similarly, Lonsdale, Hodge, \& Rose (2009) found that burnout was positively correlated with amotivation and controlled forms of motivation and negatively correlated with autonomous forms of self-determination. The results also found "autonomy and competence were significant predictors of burnout" (p. 792).

A final model, and the guiding model for the current research, is Raedeke's (1997) model based on sport commitment. Raedeke believed that athletes participate in sport for three main reasons: the athlete wants to, the athlete feels as if they have to, or a combination of the two. Raedeke hypothesized that those that felt they had to participate, the entrapped athletes, would show higher levels of burnout than athletes who participated because they wanted to. He investigated 236 adolescent swimmers who participated in the highest level for their age group. The investigator used the preliminary burnout measure developed by Eades (Eades Burnout Inventory; 1990) and also surveyed the athletes on the perceived benefits and costs associated with swimming, swimming enjoyment, personal investments, alternative attractiveness social constraints, swim identity using the AIMS (Brewer, 1993) and perceived control. Raedeke grouped the athletes in one of four profiles based on their determinants of commitment; enthusiastic, malcontented, obligated, and indifferent. The cluster analysis accounted for 59\% of the variance in the burnout dimensions. The enthusiastic swimmers demonstrated the lowest burnout scores. Swimmers in the malcontented cluster felt entrapped, namely they perceived low control and high social constraints. These swimmers also viewed swim participation negatively and, not surprisingly, had the highest burnout scores on all three burnout dimensions when compared to the other swimmers. The obligated swimmers also perceived low control and high social constraints but did view swimming as neither positive nor negative. These swimmers reported moderate levels of burnout but lower scores than the malcontented swimmers. Raedeke 
concluded that looking at burnout in a commitment perspective does not deny that stress and burnout are related, rather the difference in a commitment and stress outlook on burnout is that using a commitment perspective can help identify under which specific conditions elevated stress may be associated with burnout. Specifically, Raedeke believed these conditions were fulfilled when the athlete felt entrapment from the sport and environment.

\section{Measurement of Burnout}

In the early stages of burnout research, the investigation of the concept was hampered by a lack of a reliable sport specific inventory. Initially, researchers chose to use Maslach and Jackson's Maslach Burnout Inventory (MBI; 1986), which was originally established to measure burnout in the human services field. The MBI was designed with three subscales including reduced accomplishment, physical and emotional exhaustion and depersonalization. Even though the conceptual framework for the MBI was founded, the non-sport specific nature was a problem. In response to the lack of a sports specific instrument, the Eades Athlete Burnout Inventory (EABI; Eades, 1990) was created. The inventory contains six subscales negative selfconcepts of athletic ability, emotional and physical exhaustion, psychological withdrawal from sport and devaluation of sport participation, devaluation by coach and teammates, congruent athlete-coach expectations, and personal and athletic accomplishment. One major problem with the EABI was the lack of theoretical foundation in its development. Instead of theory driving the creation of the EABI, the creators used descriptions and anecdotal evidence in its development. This absence of a theoretical basis makes the EABI difficult to interpret (Cresswell \& Eklund, 2006). Other major problems with the EABI include the over-reliance on a unidimensional burnout score and low internal consistency with the subscales (Gould et al., 1996).

Due to the inadequacies of previous scales and the lack of a proven sport specific measurement for burnout, Raedeke and Smith (2001) developed the Athlete Burnout Questionnaire and established initial validity evidence through three studies. In the first study, Raedeke and Smith hoped to assess the factor structure of the initial ABQ. Swimmers were given the $\mathrm{ABQ}$, and analysis resulted in an internally consistent burnout measure consisting of emotional/physical exhaustion, reduced sense of accomplishment and devaluation. In the second phase of the study, the researchers hoped to confirm the measure's factor structure as well as examine the relationship with stress coping, social support, enjoyment, and motivation. Results again confirmed the structure of the measure with minor modifications. As expected, the 
burnout subscales showed positive relationships with stress and negative relationships with coping, social support, amotivation, and enjoyment, and a negative correlation with intrinsic motivation. The first two phases of the study investigated the ABQ in relation to swimmers, and the final phase of the study hoped to cross-validate the findings with athletes in multiple sports. Additional aims of the third phase were to further confirm the structure of the ABQ and correlations with theoretically related constructs and test the test-retest reliability. Athletes from Division II and Division III schools were given the ABQ as well as measures for anxiety, enjoyment, commitment and motivation. As expected, burnout was positively related to competitive trait anxiety and amotivation, and negatively related to enjoyment, commitment, and intrinsic motivation. Stability for the measure was also established over a 7- to 9-day period. On the bases of these studies, Raedeke and Smith were successful in developing a sport-specific measure of burnout that was based upon theory.

Cresswell and Eklund (2006) wanted to further establish validity of the Athlete Burnout Questionnaire. In their study, multi-trait/multi-method analyses were used to assess the convergent, discriminant and construct validity of the $\mathrm{ABQ}$, Maslach Burnout Inventory-General Survey (Maslach \& Jackson, 1996), and Depression Anxiety Stress Scale (DASS; Lovibond \& Lovibond, 1995). The results of the analysis support the convergent and divergent validity of both the ABQ and the MBI-GS subscales, but the MBI-GS displayed weaker results than the ABQ. Cresswell and Eklund suggest that these results can give researchers additional confidence in using the ABQ with an athlete population and give additional support to the subscales within the ABQ. The Cresswell and Eklund study combined with the Raedeke and Smith (2001) findings demonstrate that the most useful inventory to measure athlete burnout currently is the ABQ.

\section{Early Studies on Burnout in Adolescent Athletes}

One of the most influential set of studies in the realm of sports burnout are those conducted by Gould and his colleagues. Their multi-study project investigated reasons for burnout in youth junior-elite tennis players. The study consisted of three parts; a quantitative analysis of youth tennis players examining the differences between individuals who experienced burnout compared to those who did not (Gould, Udry, Tuffey, \& Loehr, 1996), a qualitative investigation with the athletes who qualified as burned out from the quantitative study (Gould, Tuffey, Udry \& Loehr, 1996) and a case study follow-up that investigated three athletes from the 
original study to demonstrate the uniqueness of each case of burnout (Gould, Tuffey, Udry, \& Loehr, 1997). All three investigations examined burnout as a reciprocal interaction of personal and situational factors. By conducting the investigations with this guideline, both factors were considered equally important, and both factors were necessary for consideration to better understand burnout and its implications. The presence of both factors did not guarantee burnout, but it would be highly unlikely to experience burnout in the absence of the two factors. The quantitative study (1996) was conducted with 62 tennis athletes, 32 who had experienced burnout symptoms and 30 who had not experienced symptoms. All 32 of the individuals in the burnout group had ceased participation of tennis for some time. The sample was highly skilled with participants having a mean national ranking of $55(\mathrm{SD}=36.1)$ The researchers administered a series of self-report questionnaires to all participants that assessed levels of athlete burnout, motivation, perfectionism, anxiety, athletic identity and coping strategies used by the individuals. Gould et al. found the athletes suffering from burnout were higher on perceived parental criticism and expectations, were more concerned over mistakes and had lower personal standards. Surprisingly, the differences of athletic identity between burned out and non-burned out athletes were non-significant. One hypothesis for this non-significant relationship was the scale used to measure athletic identity was the original unidimensional construct first generated by Brewer et al. (1993).

In phase 2 of Gould et al. (1996), the researchers identified the 10 athletes who reported the highest levels of burnout in the first phase of the study and conducted semi-structured qualitative interviews with each of them. Through these interviews, general themes were developed. They found two major categories of burnout symptoms emerged; mental symptoms and physical symptoms. The mental symptoms included staying motivated, lacking motivation/energy, negative feeling-affect, feelings of isolation, concentration problems and high and low moods and physical symptoms including injuries, illness or lack of energy, and being physically asymptomatic. Other general themes that emerged from the data not included in the mental and physical symptoms include physical concerns (e.g., being sick, poor play), logistical concerns (e.g., demands of tennis, travel concerns, adjusting to school), social/interpersonal concerns (e.g., dissatisfaction with social life, negative parental influence), and the largest dimension was psychological concerns (e.g., unfulfilled/inappropriate expectations, lack of enjoyment, motivational concerns, personality not conducive to competitive tennis). 
The qualitative case study (1997) by Gould et al. highlighted differences among three athletes who were suffering from burnout to show that despite the similarities in athletes who are burned out, key differences exist in each case of burnout. The most significant form of stress in the athletes involved in the study were overtraining and self-pressure for athlete A parentpressure and social influences for athlete B, and outcome goals, a narrow focus, and overtraining for athlete $\mathrm{C}$. One important factor in the investigative analysis is that even though all three athletes suffered from different sources of stressors, one factor that appeared in all three cases was some level of perfectionism. The case study by Gould et al. showed that even though the burnout syndrome may share similarities, each case is unique to the individual.

\section{Consequences of Burnout}

The literature on consequences of burnout in adolescent athletes has been surprisingly small for the amount of research conducted in the field. In Gould et al.'s studies $(1996 ; 1997)$, the researchers found two types of burnout: cessation of sport and active burnout. Even though participants often suffer from burnout in sports, it does not always lead to cessation of participation (Weinberg \& Gould, 2007). Individuals suffering from burnout may feel obligated to continue participation due to many external factors including financial reasons, prestige of their position, a fear of routine change and pressure to continue due to outsider expectations. Even though an individual is suffering from burnout, they can continue to participate until the costs of continued involvement outweigh the benefits of the activity. Cessation of activity is the best known consequence of burnout but not the only consequence. Multiple studies have investigated these consequences in depth and will be reviewed briefly.

Goodger and colleagues (Goodger, Wolfenden \& Lavallee, 2007) conducted a qualitative study with national junior tennis players that investigated consequences of burnout during play, immediately after sport cessation and the long-term consequences. All 6 of the athletes that participated in the study had suffered symptoms of burnout that led to a permanent end in participation. The athletes were former national junior tennis players (ages $15-21$ ) and had attended the National Tennis Academies for training camps. The researchers investigated the symptoms and consequences of each of three symptoms of burnout. The symptoms that emerged for emotional and physical exhaustion were negative affect, feelings of isolation, lack of motivation and energy, physical complaints such as lack of energy and feeling mentally drained. The consequences of burnout in athletes included lethargy, negative feelings toward tennis, 
withdrawal and avoidance behavior. In the devaluation dimension, six themes emerged that were condensed into the higher order theme of decreased motivation. Consequences for devaluation were regret of participation, negative reflections on their tennis experiences, and the inability to develop other aspects of their self-identity. Symptoms of a reduced sense of accomplishment were lack of improvement, underperformance, inconsistent performance and a lack of training gains. Consequences of a reduced sense of accomplishment were: lack of focus and direction, lowered self-esteem, departure of the sport, and performance frustration. The researchers concluded that the athletes developed a unidimensional identity and their confidence and self esteem hinged on their performance in sport. This study was important in examining the consequences associated with sport burnout and demonstrated that even though cessation of sport participation is the easiest consequence to see in an athlete suffering from burnout, it is not the only consequence.

Coaches also shared similar perspectives of symptoms and consequences of burnout in athletes that they coached. In a study by Raedeke and colleagues (Raedeke, Lunney \& Venables, 2002), coaches identified common identifiers of burnout as withdrawal, reduced sense of accomplishment, physical and psychological exhaustion, and devaluation of sport. Coaches also described symptoms of burnout that they had seen. Examples of these symptoms include withdrawal from training and teammates, lack of improvement, diminished sense of progress, general detachment from swimming, hatred of the sport and overall exhaustion. The symptoms and identifiers described by coaches were also seen in the study by Goodger and colleagues (2007) that demonstrates that not only can athletes recognize burnout but coaches can as well.

In summary, the studies described in the previous paragraphs provide some descriptive results regarding the consequences of high levels of burnout in adolescent athletes. Other studies have examined the causes of burnout. The results of these studies are summarized in the next section.

\section{Causes of Burnout}

Several causes of burnout have been hypothesized in the literature. Common causes of burnout include overtraining, the socio-cultural environment that is sport and personality factors to name a few. Potential causes for the burnout syndrome associated with the environment of the sport include low autonomy in training (Coakley, 1992, Gustafsson, Hassmén, Kenttä, \& Johansson, 2008) and a feeling of entrapment (Raedeke, 1997; Gould et al., 1996; Gustafsson et 
al., 2008). Lemyre, Hall and Roberts (2008) found that the motivational climate was important in athletes' burnout levels with a more task oriented climate showing negative correlations with burnout while an ego orientation positively predicted burnout levels. The Raedeke study that interviewed coaches (2002) also involved the environment of sport with possible causes of burnout being outside of the individual and including pressure from parents, pressure from coaches, pressure to win, overtraining and pressure from friends outside of sport to decrease their involvement. The burnout phenomenon has also been investigated from the self-determination perspective. Multiple studies have found intrinsic motivation is negatively correlated with burnout while amotivation is positively correlated with burnout (Gustafsson, et al., 2008; Cresswell \& Eklund, 2005; 2006). Personality characteristics have also been investigated as possible sources of burnout. Raedeke and Smith (2004) found that less desirable coping strategies along with unsupportive significant others lead to additional stress which, ultimately, lead to increased burnout levels in adolescent swimmers. In a review of the burnout literature, Goodger and colleagues (Goodger, Gorely, Lavallee, \& Harwood, 2007) found that a unidimensional identity was often linked to burnout, but results were mixed, and various personality traits such as maladaptive perfectionism (Gould et al., 1996; Appleton, Hall \& Hill, 2009; Hill, Hall, Appleton \& Murray, 2010) have been linked to burnout as well.

\section{Summary of Literature Review and Overview of Current Proposed Study}

As noted in the introduction to this chapter, the current proposed study focuses on three constructs that appear to be important in the adolescent sport context. These include: passion, athletic identity, and burnout. The review of the literature on these three constructs showed that each is important to the psychosocial health and well-being of the young athlete. However, there appears to be a gap in the literature with respect to the relationship between these three variables. In particular, the research and theory on the constructs of passion and athletic identity would suggest that both may be related to, or predictive of, levels of burnout in adolescent athletes.

Passion is a relatively new construct to the sport psychology field. According to the research and theory reviewed in the first section of this chapter (and summarized, in some depth, by Vallerand \& Miquelon, 2007), there are two forms of passion: harmonious and obsessive. For the most part, harmonious passion has been linked to more positive outcomes while obsessive passion is associated with more negative outcomes. Research studies have been conducted to show a link between passion and burnout in the workplace (Carbonneau et al., 
2008; Vallerand et al., 2010). The results of these studies indicated that obsessive passion was associated with, or predictive of, higher levels of burnout while harmonious passion was associated with lower levels of burnout. Because the link between the two types of passion has not yet been examined in the sport setting, the current study was designed to do so.

A second psychological construct, athletic identity, was also selected in the current study as a possible predictor of burnout levels in adolescent athletes. As noted in a previous section of this chapter, the research examining the association between these two variables has produced somewhat mixed results, although these inconsistencies may be due to the different instruments that were used. Thus, the current study was designed to examine these conflicting results using a multidimensional measure of burnout.

In summary, then, the primary purpose of the current study was to determine whether adolescent athletes' levels of sport burnout would be correlated with, or predicted by, their level and type of passion and the degree to which they identify with the athlete role. Based on the theory and research cited in this chapter, it was hypothesized that higher levels of obsessive passion would be positively correlated with, or predictive of, higher scores on the three subdimensions of burnout while higher levels of harmonious passion would be predictive of lower scores on the burnout subscales. It was further hypothesized that athletic identity would be negatively related to athletes' scores on the three burnout subscales. 


\section{Chapter Three: Methods}

The overall goal of the current proposed research study was to examine hypothesized connections between three constructs in the sport psychology literature. These constructs included passion, athletic identity, and burnout. In particular, this project was conducted with a sample of adolescent athletes. Specific detail about the methodological procedures is provided in the following sections of this chapter.

\section{Participants}

Study participants were 218 female adolescent athletes who ranged in age from 16 to 18 years $(M=16.63 ; S D=.61)$ and who were current members of a high school or high school-aged athletic team. The sample included girls from all four grades in high school. Although the majority of athletes in the study had just completed either their sophomore $(n=86)$ or their junior year in high school $(n=114)$, there were also a few who had just completed either their first year $(n=3)$ or their last year $(n=14)$ in high school. Many of the athletes were involved in multiple sports. But, for this study, each athlete was asked to choose her main sport and then to answer all study questionnaires in the packet in relation to that particular sport. Athletes identified a variety of sports including volleyball $(n=109)$, field hockey $(n=36)$, soccer $(n=20)$, synchronized skating $(n=18)$, skating $(n=12)$, basketball $(n=6)$, track $(n-4)$, cross-country $(n=4)$, softball $(n=2)$, tennis $(n=1)$, gymnastics $(n=1)$, and cheerleading $(n=1)$. The majority of the athletes indicated that their participation in their primary sport had been at the high school varsity level $(n=135)$, but a few indicated involvement at the junior varsity $(n=19)$ or first year level $(n=1)$. Athletes were recruited from those who were in attendance at a summer sports camp.

\section{Procedure}

Data collection procedures for the research project included two main components. Participants were involved in a larger research project and were recruited at summer sport camps affiliated with universities throughout the midwestern and western parts of the United States. Prior to the beginning of each summer camp, email or phone contact was made with camp directors who were informed about the research project. Any questions the camp director had were answered by the principal researchers, and permission was received from the directors to administer the questionnaires to the athletes at their camps. Specifically, signed permission was obtained from each camp director prior to any contact with the athletes (shown in appendix: Sports Camp Director Agreement to Participate Form). 
Once approval from a camp director was obtained, a specific day and time were identified for data collection. On the day of data collection, a member of the research team met with the athletes who were eligible for participation in the study. Athletes were provided with a brief description of the research project. They were asked to read the permission and assent form on the cover of the surveys and to ask any questions they may have had. The individuals administering the surveys assured athletes that all responses would be collected in an anonymous format, and that their names, the names of their high schools and their coaches would not be collected. A sample script can be seen in the appendix (shown in appendix: Script). Surveys were distributed and athletes were instructed to read the front cover of the survey that contained the participant information and assent form. Upon completion, the athletes were instructed to tear off the front page of the survey and keep a copy in case of additional questions or comments (shown in appendix: Participant Information and Assent Form). When athletes had completed their survey packet, they submitted the completed packet to the person(s) collecting the data.

\section{Instrumentation}

A multi-section inventory was used to collect data. The inventory contained a demographics page, and measures that included The Passion Scale (Vallerand et al., 2003), the Athletic Identity Measurement Scales (Brewer, 1993) and The Athlete Burnout Questionnaire (Raedeke, 1997). Before beginning the survey, each athlete was asked to identify (and write down) a specific sport team (e.g., soccer, field hockey) and competitive level (e.g., frosh, junior varsity, varsity) that she would use when answering all questions on the survey.

\section{Demographics Page}

The demographics page included questions assessing age, class standing, gender, sport experience, sport leadership experience, siblings and their sport experience, mother and father's occupations and highest education level, and the gender of the team coach that they had chosen for their reference point in responding to the survey.

\section{Passion Scale}

The Passion Scale (Vallerand et al., 2003) was used to assess the level of passion of high school-aged athletes in the study. The passion scale is comprised of two subscales, each containing 7 items that assess the two distinct types of passion: harmonious passion and obsessive passion. Each item is responded to on a 7-point Likert scale ranging from 1 (do not agree at all) to 7 (completely agree). A sample item from the obsessive passion subscale is, "I 
have difficulties controlling my urge to engage in my activity", while a sample question for harmonious passion would be "My activity is in harmony with other things that are part of me." The Passion Scale has been demonstrated to possess adequate factorial structure and internal consistency across a range of activities including sport (Vallerand et al., 2003, Study 1; Rousseau et al., 2002; Vallerand et al., 2006, Study 1). Previous reported Cronbach's alpha values ranged from .70 - .79. In the current study, the two passion subscales exhibited adequate internal consistency (i.e., at or above a .70 criterion level as recommended by Nunnally and Bernstein, 1994), with obtained Cronbach's alphas of .82 and .90 for harmonious and obsessive passion, respectively.

\section{Athletic Identity Measurement Scale}

The AIMS was initially developed as a unidimensional construct. However a three subscale version of the AIMS has demonstrated better fit (Brewer and Cornelius, 2001). The AIMS consists of seven items split into three subscales: exclusivity, social identity and negative affectivity. Individuals respond to each item on a 7-point Likert scale ranging from 1 (strongly disagree) to 7 (strongly agree). A sample item from the social identity subscale, which contains three items, is "I consider myself an athlete", a sample item from the exclusivity subscale, which has two items, is "Sport is the most important part of my life", and a sample item from the negative affectivity subscale, which contains two items, is "I feel bad about myself when I perform poorly in sport." Overall AIMS scores range from 7 to 49, with higher scores indicating a stronger athletic identity. Norms were also reported by Brewer and Cornelius with mean scores for males $(\mathrm{M}=35.92, \mathrm{SD}=8.59)$ significantly higher than mean scores for females $(\mathrm{M}=$ $30.15, \mathrm{SD}=10.68)$, indicating that males tend to have higher athletic identity than females.

Cronbach's alphas calculated for the current study showed that only one of the three subscales, as well as the total AIMS score, showed adequate internal consistency (i.e., at or above .70). That is, alpha values of .82 were obtained for the exclusivity subscale and .77 for the total AIMS scale. For the social identity subscale, the obtained Cronbach's alpha level of .62 was below the criterion level of .70. However, deletion of item 3 in the subscale resulted in an alpha level of .70. Thus, this was the subscale score (e.g., with deletion of one item) that was used for the current study. Finally, the alpha coefficient obtained for the negative affectivity subscale was .63. This value is below the criterion score of .70 as recommended by Nunnally and Bernstein (1994). However, as demonstrated by psychometricians (e.g., Cortina, 1993), 
alpha values are a function of the number of items that comprise the scale. In particular, the negative affectivity subscale was comprised of only two items, thus leaving it susceptible to low internal consistency estimates. In these situations, other measurement scholars (e.g., Schmitt, 1996) have suggested that alpha values as low as .50 may be considered acceptable for use in behavioral research. Due to the importance of this particular subscale to the current study and given that this is an exploratory (descriptively-based) study, the decision was made to retain this subscale in the main study analyses. However, the lower internal consistency score should be noted as a possible limitation to the results of the current study.

\section{Athlete Burnout Questionnaire}

Burnout was measured by the Athlete Burnout Questionnaire (Raedeke \& Smith, 2001), a sport-specific questionnaire. The stem for each question was "How often do you feel this way?" Athletes are asked to rate the extent to which they experience each item in relation to participation motives on a 5 point Likert scale ranging from (1) "almost never", (2) "rarely", (3) "sometimes", (4) "frequently", and (5) "almost always." The ABQ is comprised of 15 items that are separated into three subscales, each containing five items. The three subscales are: devaluation of sport participation, reduced sense of accomplishment and emotional and physical exhaustion. A sample item from the reduced accomplishment subscale is "I am not achieving much in my sport,", and a sample item for devaluation is "The effort I spend in my sport would be better spent doing other things." A sample item for emotional exhaustion is "I feel so tired from my training that I have trouble finding energy to do other things." A total score for the $\mathrm{ABQ}$ is found by averaging all three subscale scores. The ABQ has demonstrated good stability over a 7- to 9-day period (Raedeke \& Smith, Study 2) and confirmatory factor analyses have revealed support for the construct validity of the three subscales (see summary of this psychometric research by Eklund \& Cresswell, 2007).

In the current study, two of the three subscales showed acceptable levels of internal consistency, as indicated by Cronbach's alphas of .88 (exhaustion) and .84 (devaluation). The third subscale, reduced accomplishment, revealed an alpha coefficient of .64. Again, this value is below the recommended criterion of .70 (Nunnally \& Bernstein, 1994) but above the minimal level of .60 specified by others (e.g., Devellis, 2003; Schmitt, 1996). Thus, this subscale was also retained, with appropriate cautionary notes about its level of internal item consistency. Statistical Analyses 
Descriptive statistics for all relevant study variables were computed and screened for linearity and normality. A set of multivariate analyses of variance (MANOVAs) was conducted in order to determine if there were any differences between younger and older athletes in regard to the primary study variables. Preliminary univariate Pearson correlational analyses also were conducted to examine the degree of correlation between the variables within each construct (passion, athletic identity, and burnout) so that any multicollinearity issues could be identified prior to conducting the main study analyses. The correlational analysis was also conducted to investigate the relationship between harmonious and obsessive passion and the athletic identity subscales. Finally, to test the main study hypotheses regarding the links between adolescents' athletic identity, passion, and burnout, multivariate multiple regression and canonical correlational procedures were used. 


\section{Chapter Four: Results}

This study was conducted to determine whether adolescent female athletes' levels of sport burnout would be correlated with, or predicted by, their level and type of passion and the degree to which they identify with the athlete role. It was hypothesized that higher levels of obsessive passion would be positively correlated with, or predictive of, higher scores on the three subdimensions of burnout while higher levels of harmonious passion would be predictive of lower scores on the burnout subscales. In addition, it was hypothesized that athletic identity would be negatively related to athletes' scores on the three burnout subscales.

To examine the primary study purpose, a variety of statistical procedures were used. The results of these analyses are presented in the following sections. In the first section, descriptive statistics are presented. In the second section, the results from preliminary analyses are described. Finally, in the third section, the main study analyses are presented.

\section{Descriptive Statistics}

The descriptive statistics computed for the three subscales from the burnout scale (see Table 1) revealed that the majority of the female athletes in this sample showed low-to-moderate scores on each burnout dimension. Specifically, examination of frequency distributions corresponding to this data revealed that the majority of athletes $(88.9 \%, 62.9 \% 88.5 \%)$ scored 3.00 or below (i.e., sometimes to almost never) on reduced accomplishment, emotional/physical exhaustion and sport devaluation, respectively. Between $6 \%$ and $29 \%$ of the athletes scored between a 3.00 and a 4.00 (i.e., sometimes to frequently) on the three burnout subscales, and only $0 \%$ to $7.9 \%$ scored between 4.00 and 5.00 (i.e., frequently to almost always). A total of 10 of the participants in this study scored greater than 3.00 on all three burnout subscales, a proportion comparable to previous athlete burnout research (see Black \& Smith, 2007; Eklund \& Cresswell, 2007).

Examination of the standard deviation and range scores for the three burnout subscales revealed what appear to be similar standard deviations across the three subscales $(.61, .84$, and .80 ), but the full range of scores did differ across subscales. Specifically, only the exhaustion subscale revealed use of a full range of scores (1 to 5), while the upper range values for both the reduced accomplishment and devaluation subscales were less than the maximum score of 5 (high scores of 3.8 for reduced accomplishment and 4.8 for devaluation). In summary, the descriptive data does indicate relatively low burnout levels, but the standard deviations and range scores do 
suggest considerable inter-individual variability within the sample of adolescent athletes. All burnout subscales were also checked for normality, and results indicated that all score sets were normally distributed.

The descriptive data for the subscales from the Passion Scale and the AIMS (see Table 2) revealed interesting results. In particular, the results indicate that this sample of female athletes exhibited high levels of passion for their sport. The mean for harmonious passion was 5.90 (on a scale of 1 to 7 ) and $98.6 \%$ of the sample scored above the midpoint (3.5) for the scale. The mean value for the obsessive passion subscale was 4.41 with $68.8 \%$ of the sample scoring above the midpoint (3.5) for the scale. Harmonious passion appeared to have a smaller (but not necessarily significantly different) standard deviation than did obsessive passion (.82 and 1.45 respectively), and the range of scores for the two subscales also differed somewhat. Scores on the harmonious passion subscale ranged from a low of 2.71 to a high of 7.00 while the obsessive passion subscale showed a full range of scores (1.00 to 7.00). Both subscales were checked for normality, and both sets of scores were found to be normally distributed.

The mean scores from the AIMS also fell above the midpoint on each of the subscales as well as on the total AIMS score (Table 2). The AIMS subscale with the highest mean score was social identity with a score of 6.38 on a scale of 7 . The mean scores for the other two AIMS subscales, exclusivity and negative affectivity, were also above the midpoint of the 7-point scale, landing at 4.39 and 5.21 respectively. The normative scores reported by Brewer and Cornelius (2001) revealed that female athletes in their study scored an average of 4.31 (on a 7 point scale) on the total AIMS. The athletes in the current sample exhibited what appear to be higher (but not necessarily significantly higher) average scores (5.43) on the total AIMS.

Standard deviations for the three AIMS subscales (Table 2) revealed similar values for the exclusivity and negative affectivity scores (1.56 and 1.40 respectively) and smaller standard deviation values for social identity and AIMS total (.84 and .93 respectively). All AIMS subscale scores were checked for normality. Exclusivity, negative affectivity and AIMS total scores were normally distributed. However, the distribution of the social identity scores did exhibit a negative skew (-2.17), and examination of the frequency distribution revealed that this negative skew occurred because the majority of the girls in the sample (77.2\%) scored between 6.00 and 7.00 (on a 7-point scale) on this subscale while the remaining 18\% scored at a much lower level. Given the type of female athletes in this sample, the somewhat skewed distribution 
may not be surprising. That is, the athletes in this study sample were recruited for participation from among those individuals attending high level summer sport camps and thus likely were the more talented, high achieving athletes within the broader population of high school-aged female athletes.

To summarize, the sample of athletes in this study, on average, scored below the midpoint on all three burnout subscales and above the midpoint on the two subscales of the Passion Scale and on the three subscales of the AIMS. Again, however, there was also evidence of inter-individual variability within the sets of scores.

\section{Preliminary Results}

Two sets of preliminary analyses were conducted for this study. The results of these procedures are presented in the following sections.

\section{Age or Academic Level Differences}

Given that study participants did range somewhat in age and academic level (freshman to senior year in school), two one-way MANOVAs were conducted to determine if athletes' level of passion, athletic identity or burnout differed as a function of their year in high school. The first MANOVA was conducted to determine if athletes' scores on the three burnout subscales from the ABQ differed across their academic level. The independent variable for this analysis was academic level (freshman/sophomore and junior/senior). The dependent variables consisted of the three subscales from the ABQ. The results revealed a non-significant academic level main effect, Wilks' $\lambda=.98 ; F(3,190)=1.42, p<.24, \eta^{2}=.02$. These results demonstrated that freshman and sophomores did not differ from junior and seniors on any of the burnout dimensions.

A second MANOVA was conducted to determine if athletes' scores on any of the subscales from the AIMS and the Passion Scale differed as a function of athletes' academic level. The dependent variable consisted of the three subscales from the AIMS (social identity, exclusivity and negative affectivity) and the two subscales (harmonious and obsessive passion) from the passion scale. The results revealed a non-significant main effect for academic level, Wilks' $^{\prime}=.95 ; F(5,192)=2.18, p<.06, \eta^{2}=.05$. Because this main effect did approach significance, the univariate $F$-values were examined and are reported in Table 3 . As these results show, all follow-up univariate tests were not significant. Thus, it appears that freshman and 
sophomores did not differ from junior and seniors on any of the athletic identity or passion subscales.

In summary, the results demonstrated that freshman and sophomore, and junior and senior athletes did not significantly differ on their levels of burnout, athletic identity or passion. Thus, the main study analyses were conducted without regard to athletes' academic level.

\section{Univariate Correlational Analyses}

A series of univariate Pearson correlational analyses were conducted to examine the strength of the relationship between the three variables comprising the dependent variable set (burnout subscales) and the five variables that were to be included in the main analyses as the independent variable set (Passion and AIMS subscales). The correlational analyses were conducted to assess the possibility of multicollinearity within each data set but also to examine the degree of the relationship between the passion and athletic identity subscales.

The results of the univariate correlational analysis for the burnout subscales are presented in Table 4. Examination of these coefficients indicate a range from .39 to .58 , with all coefficients being significant at $p<.01$. Thus, the burnout subscales are positively and significantly correlated with each other (similar to results obtained by other researchers as discussed in a comprehensive review by Eklund and Cresswell, 2007). However because the coefficients were all less than .70, multicollinearity is not an issue in this study.

The results of the univariate correlational analysis for the Passion and AIMS subscales are presented in Table 5. These results show that the correlation between harmonious and obsessive passion was positive $(.52)$ and significant $(p<.01)$. In addition, the three AIMS subscale scores were positively and significantly correlated to each other. The obtained coefficients ranged from .35 to .49 and were all significant at $p<.01$.

The degree of correlation that existed between the passion and AIMS subscales was also assessed. These results (Table 5) indicate that both of the passion subscales are positively and significantly related to all three of the AIMS subscales. However, examination of the relative size of these coefficients suggests that the two types of passion may be somewhat differentially related to the three AIMS scores. Thus, a Fisher's Z test was used to compare the correlational coefficients. The results of this series of tests revealed that the correlational coefficients representing the relationship between the AIMS social identity subscale and the harmonious $(r=$ $.47)$ and obsessive passion $(r=.33)$ subscales were not significantly different from each other $(p$ 
$=.10)$. However, the coefficients for the other two subscales from the AIMS were different. That is, the correlation between obsessive passion and exclusivity $(r=.62)$ was significantly higher $(p<.00)$ than was the correlation between harmonious passion and exclusivity $(r=.35)$. Similarly, the correlation between obsessive passion and negative affectivity $(r=.62)$ was significantly higher $(p<.05)$ than that between harmonious passion and negative affectivity $(r=$ .48). Thus, athletes who score high on obsessive passion are also more likely to score higher on exclusivity and negative affectivity than are athletes who score high on harmonious passion. It should also be noted that none of the correlations between the variables exceeded .70. Thus, multicollinearity is not an issue for this study.

\section{Main Study Analyses}

To test the main study hypothesis that athletes' level of passion and athletic identity would be related to, or predictive of, their levels of burnout, a multivariate multiple regression with follow up canonical correlational analysis was conducted. The dependent variables were the three subscale scores obtained from the ABQ, and the predictor or independent variables were the two passion scores (harmonious and obsessive) and the three subscales from the AIMS (self-identity, exclusivity, and negative affectivity).

The results of this analysis revealed a significant relationship between the two data sets, Wilks' $\lambda=.57 ; F(15,491.78)=7.29, p<.00$. These results indicate that the set of predictor variables (Passion and AIMS subscales) did explain a significant amount of the variability between adolescent females in their levels of burnout.

To determine which of the independent variables were most related to, or predictive of, which burnout scores, the results of the canonical correlational analysis were examined. These results revealed two significant canonical functions $\left(R_{1}=.53, R_{1}{ }^{2}=.28, p<.00 ; R_{2}=.42, R_{2}{ }^{2}=\right.$ $.18, \mathrm{p}<.00)$. To determine which variables within each function contributed to the relationship between the two sets of data, the structure coefficients were examined (Courville $\&$ Thompson, 2001). These values are presented in Table 6. A criterion value of .40 was used to interpret the structure coefficients (at least 16\% or higher of shared variance, Tabatchnick \& Fidell, 2007). For the first function, low scores on the harmonious passion and the social identity (AIMS) subscales were predictive of high scores on all three of the burnout subscales. In particular, the coefficient for harmonious passion (-.94) was considerably higher than the coefficient for social identity (-.50), indicating that harmonious passion was the single most important predictor of all 
three forms of burnout, but that social identity is also a significant, but lesser, contributor to the regression equation.

Examination of the canonical loadings for the second canonical function revealed that low levels of exhaustion and high levels of devaluation were predicted by low scores on obsessive passion and low scores on all three of the subscales from the AIMS. Again, examination of the relative sizes of the coefficients indicates that negative affectivity was the highest predictor with obsessive passion loading second in order. The redundancy indices for the two canonical functions indicated that $18.16 \%$ of the variance in the dependent variables was explained in the first function, and an additional 3.44\% was explained in the second function. In summary then a total of $21.60 \%$ of the variability between athletes in their levels of burnout was explained by the independent variables (i.e., the two subscales of the Passion Scale and the three subscales of the AIMS). According to Pedhazur (1982), a redundancy index of $10 \%$ or higher suggests significant and meaningful relationships between data sets.

In general, then, the results of these main study analyses revealed that female athletes' levels of passion and athletic identity were predictive of their scores on the burnout scale. Specifically, due to the fact that the most variance in the dependent variable set was explained by the first function, it appears that the single best predictor of high burnout is a low score on the harmonious passion subscale. However, low scores on all of the other predictor variables were also significantly predictive of burnout. In particular, low scores on obsessive passion, combined with low scores on all three of the AIMS scale appear to be predictive of high scores on sport devaluation but low scores on physical and emotional exhaustion. 


\section{Chapter Five: Discussion}

The primary purpose of the study was to determine whether adolescent female athletes' levels of sport burnout would be correlated with, or predicted by, their level and type of passion and the degree to which they identify with the athlete role. It was hypothesized that higher levels of obsessive passion would be positively correlated with, or predictive of, higher scores on the three sub-dimensions of burnout while higher levels of harmonious passion would be predictive of lower scores on the burnout subscales. In addition, it was hypothesized that athletic identity would be negatively related to athletes' scores on the three burnout subscales. A variety of statistical procedures were used to examine these two issues. Results of the analyses for these study hypotheses are discussed in the following sections.

The results of the main analysis revealed that there was a significant and predictive relationship between the AIMS and Passion Scale and burnout in female adolescent athletes. Two significant canonical functions explained the relationship of the variables. In the first canonical function, high levels of harmonious passion combined with high levels of social identity as an athlete were predictive of lower levels of burnout on all three dimensions from the $\mathrm{ABQ}$. In the second canonical function, high scores on obsessive passion combined with high scores on all three subscales of the AIMS were predictive of higher scores on the exhaustion dimension of burnout but lower levels of sport devaluation.

The results of these analyses provide partial support for the study's main hypothesis. Specifically, as predicted, higher levels of harmonious passion and athletic identity (especially social identity as an athlete) were related to lower levels of burnout. Unexpectedly, however, higher levels of obsessive passion were actually predictive of lower levels of one dimension (sport devaluation) of burnout. Furthermore, high levels of both obsessive passion and athletic identity were predictive of high levels of physical and emotional exhaustion. Thus, it appears that harmonious passion and athletic identity are, indeed, important predictors of low levels of burnout. However, obsessive passion may also be beneficial in lowering athletes' tendencies to experience feelings of sport devaluation. Finally, the results suggest that high levels of obsessive passion and high levels of athletic identity may be associated with higher levels of physical and emotional exhaustion - perhaps indicating that athletes who are obsessive about their sport and who identify strongly with it work harder and longer at it and thus may be at risk of higher feelings of exhaustion. 
These results contrast with previous findings on the relationship between passion and burnout in the workplace. That study was conducted by Vallerand et al. (2010) who found that the type of passion individuals held for their profession impacted their burnout levels. Those individuals with harmonious passion had lower burnout scores while individuals with obsessive passion had higher levels of burnout. Conversely, the current study found that higher levels of harmonious and obsessive passion were both related to lower levels of burnout. The contrasting perspectives from the Vallerand et al study and the current one may certainly be due to context (e.g., workplace versus competitive sport). But, another possibility may be the competitive or ability level that the current study participants were at. Specifically, in a study conducted with musicians, Mageau and colleagues (2009) found that expert performers had higher levels of both harmonious and obsessive passion than did novice performers. Furthermore, the difference in obsessive passion was much more pronounced than the differences in harmonious passion, with experts having significantly higher levels of obsessive passion as compared to the novices. The researchers used these findings to hypothesize that novices may need harmonious passion to begin skill building, but once they become experts, it may be more important to have an obsessive passion in order to continue performing. This perspective assumes, then, that obsessive passion is related to continued participation instead of withdrawal. It is possible that instead of causing burnout in individuals, obsessive passion can help the more elite athlete persist in hard times. Furthermore, obsessive passion may lead to increased feelings of an obligation to practice, which may result in increased exhaustion, but it may concurrently act to increase the importance of the activity and, thus, act as a means to reduce the other two forms of burnout, devaluation and reduced accomplishment.

The results of the current study examining the link between athletic identity and burnout appear to align with the most recent studies conducted in the area rather than with the original study conducted by Gould et al. (1997). That is, Gould and colleagues found no differences in level of athletic identity between athletes who were suffering burnout and those who were not suffering from burnout. More recent studies have not replicated this finding. Raedeke (1997), for example, found that adolescent swimmers who had the highest levels of burnout exhibited lower swimming identity scores than did other swimmers in the study. Similarly, Black and Smith (2007) found that swimmers with relatively higher burnout perceptions had lower scores on athletic identity. These more recent studies by Raedeke and Black and Smith, along with the 
present study, seem to show that a strong athletic identity may inoculate an athlete from developing higher levels of burnout. It also demonstrates that individuals who do not have this strong athletic identity may be at risk for burnout and the consequences associated with it.

The current study has multiple practical implications. Harmonious passion was found to be the single best predictor of burnout. Individuals with a harmonious passion feel free to participate in an activity as they choose, and feel no compulsion or coercion to continue in the activity. Thus, it is certainly recommended that coaches and parents should create an environment for athletes that encourage them to internalize their sport in a non-controlling way so as to allow the participant to experience feelings of autonomy.

Despite the fact that harmonious passion was found in the current study to be the best single predictor of low levels of burnout, the obsessive passion subscale scores were also negatively linked to one particular dimension of burnout (sport devaluation). This positive aspect of obsessive passion with regard to lowering burnout levels contrasts with previous findings in other domains and may signal that, for high achieving athletes both harmonious and obsessive passion are important for continued participation and success. Lastly, higher scores on all three dimensions of athletic identity were related to lower levels of all three dimensions of burnout. It is possible that a strong identification with the athlete role may inoculate an athlete from feelings of burnout.

It should also be noted, again, that all three dimensions of athletic identity, in combination with obsessive passion, were positively predictive of higher levels of athletes' perceptions of physical and emotional exhaustion. These results suggest that if an individual athlete feels very strongly that she is an athlete and feels a corresponding need to continue participation even at the costs of other activities, then that athlete may feel a level of exhaustion not seen by individuals who hold more of a harmonious passion for the activity. It is interesting that the other forms of burnout, reduced accomplishment and devaluation, were not positively related to the AIMS and obsessive passion in the second function. As noted by Eklund and Cresswell (2007) in their comprehensive review of the literature on burnout, it is possible that feelings of emotional and physical exhaustion may constitute the first signs of the burnout syndrome, and may, in turn, lead to feelings of reduced accomplishment, followed by the development of sport devaluation. If this is correct, then it is possible that individuals who display strong athletic identity and obsessive passion may be at a higher risk of further 
developing feelings of burnout all three dimensions rather than just the exhaustion dimension. Further research is needed, possibly with longitudinal data, to follow the development and progress of the burnout syndrome.

In addition to the main study analysis, another key finding from this study relates to the relationship between passion and athletic identity. Due to the relatively recent development of the passion scale, no study has yet investigated the relationship between passion and athletic identity. However Vallerand and Miquelon (2007) hypothesized that the two constructs are related. Investigating the simple correlations between the two forms of passion and the subscales from the athletic identity scale revealed that both harmonious and obsessive passion are equally (and positively) related to one's social identity as an athlete. However, while both obsessive and harmonious passion were positively linked to the other two AIMS subscales, the Fisher's Z results indicate that obsessive passion exhibited a higher correlation than did harmonious passion with exclusivity and negative affectivity. This suggests that athletes who have an obsessive passion for their sport may exhibit a greater tendency than will athletes with harmonious obsession to focus exclusively on their sport (to the detriment of other activities in their lives) and to experience negative affective feelings when they are prevented from participating.

Harmonious passion allows individuals to participate in the activity as they choose and, thus, has been shown that it almost always leads to positive consequences. Social identity is similar to harmonious passion, in that it also has a more positive connotation, rather than a negative connotation associated with the other two dimensions of athletic identity. Social identity measures how strongly an individual identifies with the sporting role. A high feeling of social identity does not make an assumption of negative ruminations or limited involvement in other activities that the other dimensions measure. Similar to the harmonious and obsessive passion dyad where harmonious passion typically leads to more positive consequences, it is possible that the social identity portion of athletic identity may be linked to more positive consequences than the negative affectivity and exclusivity dimensions. To fully investigate this phenomenon further research is needed where each dimension and their consequences are studied independently.

As stated previously, in the literature, obsessive passion is associated much more frequently with negative consequences. Participants with obsessive passion feel as if their engagement in their chosen activity is out of their control, and these feelings may lead to conflict 
with other activities in their life. This is very similar to the exclusivity subscale of athletic identity. Athletes who score very high on the exclusivity subscale feel as if their sport is the single most important aspect of their life and that it takes up a disproportionate amount of their time. If individuals feel as if sport is more important than other aspects of their life, including school and family, sport may take precedent over these areas. For example, if an individual feels as if sport is more important than family and a big tournament is the same day as a sibling's wedding that athlete may choose to attend the basketball tournament instead of the family event. This could create turmoil in the family domain. In regard to both obsessive passion and exclusivity, the individual feels as if sport is more important than other domains and may feel a need to perform in sport even while creating conflict in other domains. Much like obsessive passion, exclusivity may lead to conflicts with other life roles.

Obsessive passion also shares characteristics with the negative affectivity dimension of athletic identity. Individuals with high scores on the negative affectivity subscale would feel negative emotional responses if they were not able to train or compete as an athlete due to injury, retirement or other reasons. One study by Mageau and Vallerand (2007) illustrates how participant's emotions are influenced by obsessive passion. In this study, individuals who held more obsessive passion would participate in their activity in shorter time periods than individuals with more harmonious passion, even if participation influenced other domains negatively. This participation was attributed to the fact that the individuals' mood depended largely on participation in their activity. In journals, participants stated that their mood was negatively affected when they were not allowed to participate in their activity and they felt regret when conflicting activities prevented them from participating in their passionate activity. It seems that in both harmonious and obsessive passion there is a benefit to participation, but only in obsessive passion is there a cost for not participating. This study highlights the similarity of obsessive passion and the negative affectivity subscale of athletic identity. In both obsessive passion and the negative affectivity subscales a negative response to performing was experienced when not able to participate in an activity.

Even though this is only an initial investigation of the relationship between athletic identity and passion, several practical implications arise. Consistently in the research it seems that harmonious passion has been related to positive consequences and obsessive passion has been related to negative consequences. The results from the current study seem to show that 
exclusivity and negative affectivity are more closely related to obsessive passion. It is possible that, in future research, the athletic identity dimensions should be treated individually instead of as a unidimensional or singular construct. For example instead of reporting that athletic identity is related to another construct, it may be more beneficial to report how each subscale is related to the construct.

\section{Study Limitations}

Although this study provided some interesting results, some limitations are evident. First, the current sample was relatively limited. That is, the athletes in this study were high level, adolescent, female athletes. The fact that no males and no recreational athletes were included limits the generalizability of the conclusions. In particular, the results of this study may not necessarily generalize to collegiate or male athletes, as female high school athletes may have different perspectives regarding their burnout and passion levels than do older collegiate and male athletes. Second, the data was collected at a single time point. Thus, the relationship between the three main constructs (burnout, athletic identity, and passion) was not examined across different timepoints. Clearly, a longitudinal research project should be conducted in order to examine if and how the relationships between these variables might change with age and or across a competitive season. Third, as noted in the methods section, some of the subscales exhibited relatively low internal consistency, and the social identity subscale from the AIMS exhibited a negative skew. These measurement limitations should be considered as a cautionary note in the interpretation of the obtained data. A final limitation, consistent with previous studies conducted that investigated burnout, was the low number of athletes who are actually suffering from burnout. That is, no athletes in the current study scored at the higher end of the burnout scale (i.e., frequently to almost always) on all three dimensions of burnout. Further, $6 \%$ to $29 \%$ of athletes scored just over the midpoint on the scale on each of the three scales. Thus, the study sample did not include a large number of athletes who were at the top end of the burnout continuum.

\section{Future Research Directions}

The results of this study can also be used to identify directions for future research regarding the links between passion, burnout, and athletic identity. Some potential ideas or directions are presented in the following paragraphs. 
This study was the first (or, certainly, one of the first) that investigated the relationship between passion and burnout in the sporting realm. Certainly, additional research studies are needed to examine these links in other samples. In particular, it would be interesting to determine if the same or different results would be obtained in samples that include males and/or individuals who participate in sport at a more recreational or, alternatively, at a higher level (e.g., collegiate sport). In addition, the relationship between passion and burnout could and should be investigated in other sport-related populations (e.g., coaches, referees, athletic administrators). A second future direction is to implement more longitudinal research projects. Specifically, it would be interesting to assess all three of the variables examined in this study (passion, burnout, and athletic identity) at multiple time points during a single competitive season or even across several seasons. Collection of this type of data would allow researchers to determine if, and how, levels of athletic identity, passion or burnout fluctuate over time, and perhaps more importantly, to determine if and how any changes in one variable might affect changes in the others. A third possibility for future research would be to select a smaller sample of athletes who are currently experiencing the highest levels of burnout in their sport and then to examine links within this specific sub-sample between burnout, athletic identity and passion.

From a more conceptual viewpoint, the results from the current study indicate that harmonious and obsessive passion are correlated with each other. However, these two variables also appear to be somewhat independent from each other. Thus, it would interesting to compare individuals who exhibit high levels of both harmonious and obsessive passion to their peers who are high in only one type of passion and low in the other. Such an analysis could be conducted by employing a $2 \times 2$ research design to investigate differences between four types of athletes (i.e., high harmonious/high obsessive passion; high harmonious/low obsessive; low harmonious/high obsessive; and low harmonious/low obsessive). Additionally, due to the relatively new development of the passion construct in the sport psychology literature, it has not yet been investigated in relation to other important constructs. Other constructs that may be related to passion levels include perfectionism, self-efficacy and confidence. Future studies should be conducted to examine the link between passion and these variables.

In conclusion, this is an important study considering the recent shift of youth sports from more recreational to more professionalized. With increased hours of participation and less time off from training, injury and burnout may possibly increase. The results of this study have 
demonstrated that passion and athletic identity are important predictors of burnout in female high school athletes. The type of passion an individual holds, as well as how strongly they identity with the athlete role will influence their continued participation and success in their sport.

Therefore, as this study demonstrated, it is important that athletes understand why they play the sport so they can hopefully continue playing without developing any burnout symptoms. 


\section{References}

Adams, G.R., Shea, J., \& Fitch, S.A. (1979). Toward the development of an objective assessment of ego identity status. Journal of Youth and Adolescence, 8, 223-237.

Amiot, C., Vallerand, R., \& Blanchard, C. (2006). Passion and psychological adjustment: A test of the person-environment fit hypothesis. Personality \& Social Psychology Bulletin, 32(2), 220-229.

Anderson, C. (2004). Athletic identity and its relation to exercise behavior: Scale development and initial validation. Journal of Sport \& Exercise Psychology, 26(1), 39-56.

Appleton, P., Hall, H., \& Hill, A. (2009). Relations between multidimensional perfectionism and burnout in junior-elite male athletes. Psychology of Sport \& Exercise, 10(4), 457-465.

Black, J., \& Smith, A. (2007). An examination of Coakley's perspective on identity, control, and burnout among adolescent athletes. International Journal of Sport Psychology, 38(4), 417-436.

Brewer, B. (1990). Athletic identity as a risk factor for depressive reaction to athletic injury. Unpublished doctoral dissertation, Arizona State University, Tempe.

Brewer, B. (1993). Self-identity and specific vulnerability to depressed mood. Journal of Personality, 61(3), 343-364.

Brewer, B., Boin, P.D., \&Petipas, A.J. (1993, August). Dimensions of athletic identity. Paper presented at the annual meeting of the American Psychological Association, Toronto, Ontario, Canada.

Brewer, B., \& Cornelius, A.E. (2001). Norms and factorial invariance of the Athletic Identity Measurement Scale. Academic Athletic Journal, 15, 103-113.

Brewer, B., Van Raalte, J., \& Linder, D. (1993). Athletic identity: Hercules' muscles or Achilles Heel? International Journal of Sport Psychology, 24(2), 237-254.

Carbonneau, N., Vallerand, R., Fernet, C., \& Guay, F. (2008). The role of passion for teaching in intrapersonal and interpersonal outcomes. Journal of Educational Psychology, 100(4), 977-987.

Carver, C.S., Scheier, M.F., \& Weintraub, J. K. (1989). Assessing coping strategies: A theoretically based approach. Journal of Personality and Social Psychology, 56, 267-283. 
Cecić Erpič, S., Wylleman, P., \& Zupančič, M. (2004). The effect of athletic and non-athletic factors on the sports career termination process. Psychology of Sport \& Exercise, 5(1), 45 $-59$.

Chih-Chien, W., \& Yi-Shiu, C. (2007). Harmonious passion and obsessive passion in playing online games. Social Behavior \& Personality: An International Journal, 35(7), 997-1005.

Coakley, J. (1992) Burnout among adolescent athletes: A personal failure or social problem? Sociology of Sport Journal, 9, 271-285.

Cortina, J.M. (1993). What is coefficient alpha? An examination of theory and applications. Journal of Applied Psychology, 78, 98-104.

Courville, T. \& Thompson, B. (2001). Use of structure coefficients in published multiple regression articles: Beta is not enough. Educational and Psychological Measurement, $61,229-248$.

Cresswell, S., \& Eklund, R. (2005). Motivation and burnout among top amateur rugby players. Medicine \& Science in Sports \& Exercise, 37(3), 469-477.

Cresswell, S., \& Eklund, R. (2006). Changes in athlete burnout over a thirty-week rugby year. Journal of Science \& Medicine in Sport, 9(1-2), 125-134.

Crites, J.O. (1978). Career Maturity Inventory administration \& use manual ( $2^{\text {nd }}$ Ed.). Monterey, CA: CTB/McGraw-Hill.

Crowne, D.P., \& Marlowe, D. (1960). A new scale of social desirability independent of psychopathology. Journal of Consulting Psychology, 24, 349-354.

Csikszentmihalyi, M., Rathunde, K., \& Whalen, S. (1993). Talented teenagers: The roots of success \& failure. New York: Cambridge University Press.

Curry, T., \& Weiss, O. (1989). Sport identity and motivation for sport participation: A comparison between American college athletes and Austrian atudent Sport Club Members. Sociology of Sport Journal, 6(3), 257-268.

Daniels, E., Sincharoen, S., \& Leaper, C. (2005). The relation between sport orientations and athletic identity among adolescent girl and boy athletes. Journal of Sport Behavior, 28(4), 315-332.

Deci, E., \& Ryan, R.M. (1985). Intrinsic motivation and self-determination in human behavior. New York: Plenum. 
Deci, E.L., \& Ryan, R.M. (2000). The "what" and "why" of goal pursuits: Human needs and the self-determination of behavior. Psychological Inquiry, 11, 227-268.

Devellis, J. (2003). Scale development: Theory and applications. California: Sage.

Donahue, E., Rip, B., \& Vallerand, R. (2009). When winning is everything: On passion, identity, and aggression in sport. Psychology of Sport \& Exercise, 10(5), 526-534.

Eades, A.M. (1990). An investigation of burnout of intercollegiate athletes: The development of the Eades athlete burnout inventory. Unpublished master's thesis, University of California, Berkeley.

Eklund, R. C., \& Cresswell, S. L. (2007). Athlete burnout. In G. Tenenbaum \& R. C. Eklund (Eds.), Handbook of sport psychology (3rd edn., pp. 621-641). Hoboken, NJ: Wiley.

Eldridge, W.D. (1983). The importance of psychotherapy for athletic related orthopedic injuries among adults. International Journal of sport Psychology, 14, 203-211.

Fox, K.R.(1987). Physical self-perceptions and exercise involvement. Unpublished doctoral dissertation, Arizona State University, Tempe, USA.

Fox, K.R., \& Corbin, C.B. (1989). The physical self-perception profile: Development and preliminary validation. Journal of Sport and Exercise Psychology, 11, 408-430.

Gill, D. \& Deeter, T. (1988). Development of the sport orientation questionnaire. Researcher Quarterly for Exercise and Sport, 59, 191-202.

Goodger, K., Gorely, T., Lavallee, D., \& Harwood, C. (2007). Burnout in sport: A systematic review. Sport Psychologist, 21(2), 125-151.

Goodger, K., Wolfenden, L., \& Lavallee, D. (2007). Symptoms and consequences associated with three dimensions of burnout in junior tennis players. International Journal of Sport Psychology, 38(4), 342-364.

Gould, D., Tuffey, S., Udry, E., \& Loehr, J. (1996). Burnout in competitive junior tennis players: II. Qualitative analysis. The Sport Psychologist, 10, 341-366.

Gould, D., Udry, E., Tuffey, S., \& Loehr, J. (1996). Burnout in competitive junior tennis players: I. A quantitative psychological assessment. The Sports Psychologist, 10, 322-340.

Gould, D., Tuffey, S., Udry, E., \& Loehr, J. (1997). Burnout in competitive junior tennis players: III. Individual differences in the burnout experience. The Sport Psychologist, 11(3), 257276. 
Gould, D., \& Whitley, M. (2009). Sources and consequences of athletic burnout among college athletes. Journal of Intercollegiate Sports, 2(1), 16-30.

Grove, R., Fish, M., \& Eklund, R. (2004). Changes in athletic identity following team selection: Self-protection versus self-Enhancement. Journal of Applied Sport Psychology, 16(1), $75-81$.

Grove, J., Lavallee, D., \& Gordon, S. (1997). Coping with retirement from sport: The influence of athletic identity. Journal of Applied Sport Psychology, 9(2), 191-203.

Gustafsson, H., Hassmén, P., Kenttä, G., \& Johansson, M. (2008). A qualitative analysis of burnout in elite Swedish athletes. Psychology of Sport \& Exercise, 9(6), 800-816.

Hale, B. D., James, B. B., \& Stambulova, N. N. (1999). Determining the dimensionality of athletic identity: a "Herculean" cross-cultural undertaking. International Journal of Sport Psychology, 30(1), 83-100.

Harris, J. R. (1995). Where is the child's environment? A group socialization theory of development. Psychological Review, 102, 458-489.

Harter, S. (1990). Causes, correlates and the functional role of global self-worth: A life-span perspective. In R.J. Sternberg \& J. Kolligian (Eds.), Competence considered (pp. 67-97). New Haven, CT: Yale University Press.

Heyman, S.R. (1986). Psychological problem patterns found with athletes. The Clinical Psychologist, 39, 68-71.

Hill, A., Hall, H., Appleton, P., \& Murray, J. (2010). Perfectionism and burnout in canoe polo and kayak slalom athletes: The mediating influence of validation and growth-seeking. Sport Psychologist, 24(1), 16-34.

Hodge, K., Lonsdale, C., \& Ng, J. (2008). Burnout in elite rugby: Relationships with basic psychological needs fulfillment. Journal of Sports Sciences, 26(8), 835-844.

Houle, J., Brewer, B., \& Kluck, A. (2010). Developmental trends in athletic identity: A two-part retrospective study. Journal of Sport Behavior, 33(2), 146-159.

Horton, R., \& Mack, D. (2000). Athletic identity in marathon runners: Functional focus or dysfunctional Commitment?. Journal of Sport Behavior, 23(2), 101 - 119.

Kentta, G., \& Hassmen, P. (1998). Overtraining and recovery: A conceptual model. Sports Medicine Auckland, N.Z), 1, 1-16. 
Kentta, G., Hassmen, P., Raglin, J.S. (2001). Training practices and overtraining syndrome in Swedish age-group athletes. International Journal of Sports Medicine, 22, 460-465.

Lafrenière, M., Vallerand, R., Donahue, E., \& Lavigne, G. (2009). On the costs and benefits of gaming: The role of passion. CyberPsychology \& Behavior, 12(3), 285-290.

Lafrenière, M., Jowett, S., Vallerand, R., Donahue, E., \& Lorimer, R. (2008). Passion in sport: On the quality of the coach-athlete relationship. Journal of Sport \& Exercise Psychology, $30(5), 541-560$.

Lavallee, D., Gordon, S., \& Grove, J. (1997). Retirement from sport and the loss of athletic identity. Journal of Personal and Interpersonal Loss, 2, 129-147.

Lemyre, P., Treasure, D., \& Roberts, G. (2006). Influence of variability in motivation and affect on elite athlete burnout susceptibility. Journal of Sport \& Exercise Psychology, 28(1), 3248.

Lemyre, P., Hall, H., \& Roberts, G. (2008). A social cognitive approach to burnout in elite athletes. Scandinavian Journal of Medicine \& Science in Sports, 18(2), 221-234.

Lonsdale, C., Hodge, K., \& Rose, E. (2009). Athlete burnout in elite sport: A self-determination perspective. Journal of Sports Sciences, 27(8), 785-795.

Lovibond, S.H., Lovibond, P.F. (1995). Manual for the depression anxiety stress scales. Psychology Foundation Monograph. Sydney, NSW.

McNair, D. M., Lorr, M., \& Droppleman, L. F. (1971). Manual for the Profile of Mood States. San Diego, CA: Educational and Industrial Testing Services.

Mageau, G., \& Vallerand, R. (2007). The moderating effect of passion on the relation between activity engagement and positive affect. Motivation \& Emotion, 31(4), 312-321.

Mageau, G., Vallerand, R., Charest, J., Salvy, S., Lacaille, N., Bouffard, T., et al. (2009). On the development of harmonious and obsessive passion: The role of autonomy support, activity specialization, and identification with the activity. Journal of Personality, 77(3), 601-646.

Mageau, Geneviève A., Robert J. Vallerand, François L. Rousseau, Catherine F. Ratelle, and Pierre J. Provencher. 2005. Passion and gambling: Investigating the divergent affective and cognitive consequences of gambling. Journal of Applied Social Psychology 35, no. 1: $100-118$. 
Manuel, J. C., Shilt, J. S., Curl, W.W., Smith, J. A., DuRant, R. H., Lester, L., and Sinal, S.H. (2002). Coping with sports injuries: An examination of the adolescent athlete. Journal of Adolescent Health, 31, 391-393.

Markus, H. \& Wurf, E. (1987). The dynamic self-concept: A social psychological perspective. In M.R. Rosenzweig \& L.W. Porter (Eds.), Annual Review of Psychology, 38, 299-337.

Martin, J. J., Mushett, C., \& Eklund, R. (1994). Factor structure of the athletic identity measurement scale with adolescent swimmers with disabilities. Brazilian International Journal of Adapted Physical Education Research - BIJAPER, 1(1), 87-99.

Martin, J. J., Mushett, C., \& Smith, K. L. (1995). Athletic identity and sport orientation of adolescent swimmers with disabilities. Adapted Physical Activity Quarterly, 12(2), 113123.

Martin, J. J., Eklund, R., \& Mushett, C. (1997). Factor structure of the athletic identity measurement scale with athletes with disabilities. Adapted Physical Activity Quarterly, 14(1), 74-82.

Maslach, C, \& Jackson, S. E. (1981). The measurement of experienced burnout. Journal of Occupational Behaviour, 2, 99-113.

Maslach, C., \& Jackson, S.E. (1986). Maslach Burnout Inventory manual. Palo Alto, CA: Consulting Psychologists Press.

Maslach, C. \& Jackson, S.E. (1996). Maslach Burnout Inventory manual. Palo Alto, CA: Consulting Psychologists Press.

Masten, R., Tušak, M., \& Faganel, M. (2006). Impact of identity on anxiety in athletes. Kinesiology, 38(2), 126-132.

Melendez, M. (2010). Psychosocial influences on college adjustment in Division I studentathletes: The role of athletic identity. Journal of College Student Retention: Research, Theory \& Practice, 11(3), 345-361.

Murphy, G., Petitpas, A., \& Brewer, B. (1996). Identity foreclosure, athletic identity, and career maturity in intercollegiate athletes. Sport Psychologist, 10(3), 239-246.

Nunnally, J.C. \& Bernstein, I. H. (1994). Psychometric theory ( ${ }^{\text {rd }}$ ed.). NY: Mc-Graw-Hill. Pearlin, L.I. (1983). Role strains and personal stress. In H.B. Kaplan (Ed.), Psychosocial stress: Trends in theory and research. New York: Academic Press.

Pedhazur, E. (1982). Multiple regression in behavioral research. NY: Holt. 
Perrault, S. Gaudreau, P., Lapointe, M-C., \& Lacroix, C. (2007). Does it take three to tango? Psychological need satisfaction and athlete burnout. International Journal of Sport Psychology, 38, 437-450.

Philippe, F., Vallerand, R., Richer, I., Vallières, É., \& Bergeron, J. (2009). Passion for driving and aggressive driving behavior: A look at their relationship. Journal of Applied Social Psychology, 39(12), 3020-3043.

Philippe, F., Vallerand, R., Andrianarisoa, J., \& Brunel, P. (2009). Passion in referees:

Examining their affective and cognitive experiences in sport situations. Journal of Sport \& Exercise Psychology, 31(1), 77-96.

Raedeke, T.D. (1997). Is athlete burnout more than just stress? A sport commitment perspective. Journal of Sport \& Exercise Psychology, 19, 396-417.

Raedeke, T., Lunney, K., \& Venables, K. (2002). Understanding athlete burnout: Coach perspectives. Journal of Sport Behavior, 25(2), 181.

Raedeke, T., \& Smith, A. (2001). Development and preliminary validation of an athlete burnout measure. Journal of Sport \& Exercise Psychology, 23(4), 281.

Raedeke, T., \& Smith, A. (2004). Coping resources and athlete burnout: An examination of stress mediated and moderation hypotheses. Journal of Sport \& Exercise Psychology, $26(4), 525-541$.

Ratelle, C., Vallerand, R., Mageau, G., Rousseau, F., \& Provencher, P. (2004). When passion leads to problematic outcomes: a look at gambling. Journal Of Gambling Studies / CoSponsored By The National Council On Problem Gambling And Institute For The Study Of Gambling And Commercial Gaming, 20(2), 105-119.

Rip, B., Fortin, S., \& Vallerand, R. (2006). The relationship between passion and injury in dance students. Journal of Dance Medicine \& Science, 10(1/2), 14-20.

Rony, J-A. (1990). Les Passions (The Passions). Paris: Presses universitaires de France.

Rousseau, F., \& Vallerand, R. (2008). An examination of the relationship between passion and subjective well-being in older adults. International Journal of Aging \& Human Development, 66(3), 195-211.

Rousseau, F., Vallerand, R., Ratelle, C., Mageau, G., \& Provencher, P. (2002). Passion and gambling: On the validation of the Gambling Passion Scale (GPS). Journal Of Gambling 
Studies / Co-Sponsored By The National Council On Problem Gambling And Institute For The Study Of Gambling And Commercial Gaming, 18(1), 45-66.

Ryan, R.M., \& Deci, E.L. (2000). Self-determination theory and the facilitation of intrinsic motivation, social development, and well-being. American Psychologist, 55, 68-78.

Schmitt, N. (1996). Uses and abuses of coefficient alpha. Psychological Assessment, 8, 350353.

Séguin-Levesque, C., Laliberti \& Eacute, M., Pelletier, L., Vallerand, R., \& Blanchard, C. (2003). Harmonious and obsessive passion for the internet: Their associations with the couple's relationship. Journal of Applied Social Psychology, 33(1), 197-221.

Sheard, M., \& Golby, J. (2009). Investigating the 'rigid persistence paradox' in professional rugby union football. International Journal of Sport \& Exercise Psychology, 7(1), 101114.

Silva, J.M. (1990). An analysis of the training stress syndrome in competitive athletics. Journal of Applied Sport Psychology, 2, 5-20.

Smith, R. (1986). Toward a cognitive-affective model of athletic burnout. Journal of Sport Psychology, 8. 36-50.

Spielberger, C.D., Gorsuch, R.L., \& Lushene, R.E. (1970). The state-trait anxiety inventory (STAI) test manual for Form X. Palo Alto, CA: Consulting Psychologists Press.

Stephan, Y. \& Brewer, B. (2007). Perceived determinants of identification with the athlete role among elite competitors. Journal of applied sport psychology, 19, 67-79.

Tabatchnik, B.G. \& Fidell, L.S. (2007). Using multivariate statistics (5 ${ }^{\text {th }}$ ed.). Boston: Pearson. Vallerand, R.J., \& Houlfort, N. (2003). Passion at work: Toward a new conceptualization. In D. Skarlicki, S. Gilliland, \&D. Steiner (Eds.), Research in Social Issues in Management (Vol. 3, pp. 195-204). Greenwich, CT Information Age.

Vallerand, R., Mageau, G., Elliot, A., Dumais, A., Demers, M., \& Rousseau, F. (2008). Passion and performance attainment in sport. Psychology of Sport \& Exercise, 9(3), 373-392.

Vallerand, R., Mageau, G., Ratelle, C., Léonard, M., Blanchard, C., Koestner, R., \& Marsolais, J. (2003). Les Passions de l'Âme: On Obsessive and Harmonious Passion. Journal of Personality \& Social Psychology, 85(4), 756-767.

Vallerand, R.J., \& Miquelon, P. (2007). Passion for sport in athletes. In S. Jowett \& D. Lavallée (Eds.), Social Psychology in Sport (pp. 200-225). Champaign, IL: Human Kinetics. 
Vallerand, R., Ntoumanis, N., Philippe, F., Lavigne, G., Carbonneau, N., Bonneville, A., et al. (2008). On passion and sports fans: A look at football. Journal of Sports Sciences, 26(12), 1279-1293.

Vallerand, R., Paquet, Y., Philippe, F., \& Charest, J. (2010). On the role of passion for work in burnout: A process model. Journal of Personality, 78(1), 289-312.

Vallerand, R., Rousseau, F., Grouzet, F., Dumais, A., Grenier, S., \& Blanchard, C. (2006). Passion in sport: A look at determinants and affective experiences. Journal of Sport \& Exercise Psychology, 28(4), 454-478.

Vallerand, R., Salvy, S., Mageau, G., Elliot, A., Denis, P., Grouzet, F., et al. (2007). On the role of passion in performance. Journal of Personality, 75(3), 505-534.

Weinberg, R.S., \& Gould, D. (2007). Foundations of sport and exercise psychology (4 ${ }^{\text {th }}$ ed.). Champaign, IL: Human Kinetics. 
Table 1: Descriptive Data of the ABQ

\begin{tabular}{|c|c|c|c|c|c|}
\hline ABQ Subscales & Mean & $\begin{array}{l}\text { Standard } \\
\text { Deviation }\end{array}$ & $\begin{array}{l}\text { Possible range } \\
\text { of scores }\end{array}$ & $\begin{array}{l}\text { Minimum } \\
\text { Score }\end{array}$ & $\begin{array}{l}\text { Maximum } \\
\text { Score }\end{array}$ \\
\hline $\begin{array}{c}\text { Reduced } \\
\text { Accomplishments }\end{array}$ & 2.06 & .61 & $1-5$ & 1.00 & 3.80 \\
\hline Exhaustion & 2.64 & .84 & $1-5$ & 1.00 & 5.00 \\
\hline Devaluation & 1.87 & .80 & $1-5$ & 1.00 & 4.80 \\
\hline
\end{tabular}


Table 2: Descriptive Data of the Passion Scale and AIMS

\begin{tabular}{|c|c|c|c|c|c|}
\hline Subscales & Mean & $\begin{array}{l}\text { Standard } \\
\text { Deviation }\end{array}$ & $\begin{array}{c}\text { Possible range } \\
\text { of scores }\end{array}$ & $\begin{array}{l}\text { Minimum } \\
\text { Score }\end{array}$ & $\begin{array}{l}\text { Maximum } \\
\text { Score }\end{array}$ \\
\hline $\begin{array}{l}\text { Harmonious } \\
\text { Passion }\end{array}$ & 5.90 & .82 & $1-7$ & 2.71 & 7.00 \\
\hline $\begin{array}{l}\text { Obsessive } \\
\text { Passion }\end{array}$ & 4.41 & 1.45 & $1-7$ & 1.00 & 7.00 \\
\hline $\begin{array}{c}\text { Social } \\
\text { Identity }\end{array}$ & 6.38 & .84 & $1-7$ & 1.00 & 7.00 \\
\hline Exclusivity & 4.39 & 1.56 & $1-7$ & 1.00 & 7.00 \\
\hline $\begin{array}{l}\text { Negative } \\
\text { Affectivity }\end{array}$ & 5.21 & 1.40 & $1-7$ & 1.00 & 7.00 \\
\hline AIMS Total & 5.43 & .93 & $1-7$ & 2.43 & 7.00 \\
\hline
\end{tabular}


Table 3: Non Significant Academic Level Main Effect

\begin{tabular}{lccccc}
\multicolumn{1}{c}{ Variable } & $\begin{array}{c}\text { Univariate } \\
\text { F-values } \\
(5,192)\end{array}$ & $\begin{array}{c}\text { Fresh/Soph } \\
\text { Mean }\end{array}$ & $\begin{array}{c}\text { Fresh/Soph } \\
\text { S.D. }\end{array}$ & $\begin{array}{c}\text { Junior/Seni } \\
\text { or } \\
\text { Mean }\end{array}$ & $\begin{array}{c}\text { Junior/Seni } \\
\text { or }\end{array}$ \\
$\begin{array}{l}\text { Factor 1: AIMS } \\
\text { Social Identity }\end{array}$ & .54 & 6.33 & .99 & 6.42 & .74 \\
$\begin{array}{l}\text { Factor 2: AIMS } \\
\text { Exclusivity }\end{array}$ & .00 & 4.40 & 1.62 & 4.39 & 1.50 \\
$\begin{array}{l}\text { Factor 3: AIMS } \\
\text { Negative Affectivity }\end{array}$ & 1.35 & 5.06 & 1.45 & 5.29 & 1.31 \\
$\begin{array}{l}\text { Factor 4: Passion Scale } \\
\text { Harmonious Passion }\end{array}$ & 2.47 & 6.01 & & & \\
Factor 5: Passion Scale & 2.66 & 4.65 & 1.44 & & \\
Obsessive Passion & & & & & \\
& & & & & \\
\end{tabular}


Table 4: Correlational analysis for ABQ subscales

Subscale Reduced Exhaustion Devaluation Accomplishment

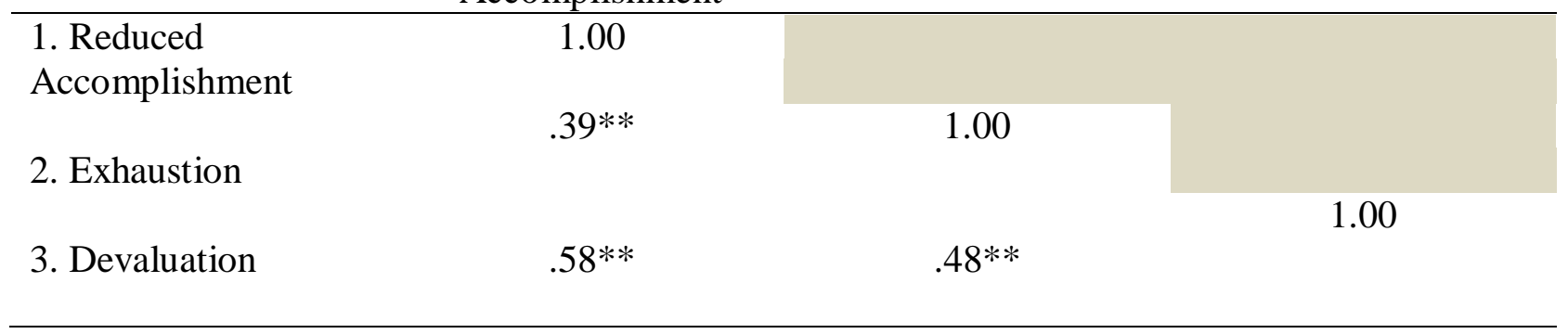

$* * \mathrm{p}<.01$ 
Table 5: Correlational analysis for Passion Scale subscales and AIMS subscales

\begin{tabular}{|c|c|c|c|c|c|c|}
\hline Subscale & $\begin{array}{c}\text { Harmonious } \\
\text { Passion }\end{array}$ & $\begin{array}{c}\text { Obsessive } \\
\text { Passion }\end{array}$ & $\begin{array}{c}\text { Social } \\
\text { Identity }\end{array}$ & Exclusivity & $\begin{array}{c}\text { Negative } \\
\text { Affectivity }\end{array}$ & $\begin{array}{r}\text { AIMS } \\
\text { Total }\end{array}$ \\
\hline $\begin{array}{c}\text { Harmonious } \\
\text { Passion }\end{array}$ & 1.00 & & & & & \\
\hline $\begin{array}{l}\text { Obsessive } \\
\text { Passion }\end{array}$ & $.52 * *$ & 1.00 & & & & \\
\hline $\begin{array}{c}\text { Social } \\
\text { Identity }\end{array}$ & $.47 * *$ & $.33 * *$ & 1.00 & & & \\
\hline Exclusivity & $.35 * *$ & $.62 * *$ & $.35 * *$ & 1.00 & & \\
\hline $\begin{array}{l}\text { Negative } \\
\text { Affectivity }\end{array}$ & $.35 * *$ & $.51 * *$ & $.43 * *$ & $.49 * *$ & 1.00 & \\
\hline $\begin{array}{c}\text { AIMS - } \\
\text { Total }\end{array}$ & $.48 * *$ & $.62 * *$ & $.68 * *$ & $.80 * *$ & $.83 * *$ & 1.00 \\
\hline
\end{tabular}

$* * \mathrm{p}<.01$ 


\section{Table 6: Follow Up Canonical Correlational Results}

Variable

Dependent Variables

Factor 1: Reduced Accomplishment

Factor 2: Exhaustion

Factor 3: Devaluation

Predictor Variables

Passion Scale: Harmonious Passion

Passion Scale: Obsessive Passion

AIMS: Social Identity

AIMS: Exclusivity

AIMS: Negative Affectivity
Function 1

.83

.78

.81

$-.94$

$-.34$

$-.50$

$-.36$

$-.09$
Function 2

.24

$-.58$

.43

$-.16$

$-.60$

$-.71$

$-.53$

$-.81$ 


\section{Appendix A}

\section{Passion Scale}

Below are 10 questions concerning athletic identity. Read each item, and then circle the number that represents how much you agree or disagree with that statement.

Do Not Agree

At all

1. This activity allows me to live a variety of experiences.

2. The new things that I discover with this activity allow me to appreciate it even more.

3. This activity allows me to live memorable experiences.

4. This activity reflects the qualities I like about myself.

5. This activity is in harmony with the other activities in my life.

6. For me it is a passion that I still manage to control.

7. I am completely taken with my sport.

8. I cannot live without my sport.

9. The urge is so strong I can't help myself from doing my sport.

10. I have difficulty imagining my life without this sport.

11. I am emotionally dependent on my sport.

12. I have a tough time controlling my need to do my sport

13. I have almost an obsessive feeling for this activity.

14. My mood depends on me being able to do my sport.

Originally developed by Vallerand et al. (2003).
Completely Agree

7

7

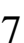

7

7

7

7

$\begin{array}{llllll}2 & 3 & 4 & 5 & 6 & 7 \\ 2 & 3 & 4 & 5 & 6 & 7\end{array}$

7

7

7

7

7




\section{Appendix B}

\section{Athletic Identity Measurement Scale - AIMS}

Below are 10 questions concerning athletic identity. Read each item, and then circle the number that represents how much you agree or disagree with that statement.

\begin{tabular}{lcc} 
Strongly & Somewhat & Strongly \\
Disagree & Agree & Agree \\
\hline
\end{tabular}

$\begin{array}{lllllllll}\text { 1. I consider myself an athlete. } & 1 & 2 & 3 & 4 & 5 & 6 & 7\end{array}$

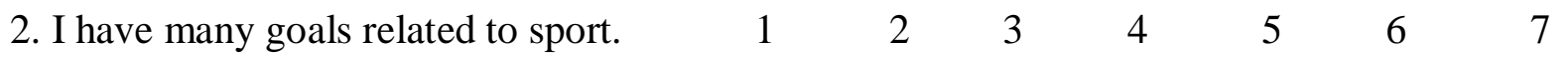

$\begin{array}{lllllllll}\text { 3. Most of my friends are athletes. } & 1 & 2 & 3 & 4 & 5 & 6 & 7\end{array}$

4. Sport is the most important part of $\quad \begin{array}{lllllllll} & 1 & 2 & 3 & 4 & 5 & 6 & 7\end{array}$ my life.

5. I spend more time thinking about $\quad \begin{array}{llllllll}7 & 2 & 2 & 3 & 4 & 5 & 6 & 7\end{array}$ sport than anything else.

$\begin{array}{llllllll}\text { 6. I need to participate in sport to feel } & 1 & 2 & 3 & 4 & 5 & 6 & 7\end{array}$

7. Other people see me mainly as an $\quad \begin{array}{llllllll}7 & 2 & 3 & 4 & 5 & 6 & 7\end{array}$ athlete.

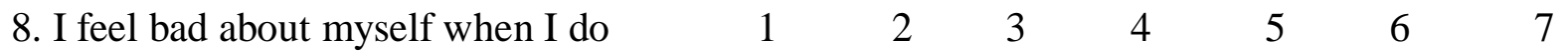
poorly in sport.

9. Sport is the only important thing in $\quad \begin{array}{llllllll}7 & 2 & 3 & 4 & 5 & 6 & 7\end{array}$ my life.

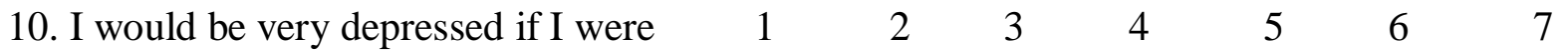
injured and could not compete in sport.

Brewer, et al. (1993).

Scoring: Low athletic identity $=10$

Moderate athletic identity $=40$

High athletic identity $=70$ 


\section{Appendix C}

\section{Athlete Burnout Questionnaire - ABQ}

Please answer the following questions as accurately and honestly as you can based on how often your experience each thought or feeling in your sport.

Almost Rarely Sometimes Frequently Almost

Never

Always

1. I'm accomplishing many worthwhile

12

5 things in my sport.

2. I feel so tired from my training that I 2

3 have trouble finding energy to do other things.

3. The effort I spend in my sport would be 1 better spent doing other things.

4. I feel overly tired from my sport

12

2

3

4 participation.

5. I am not achieving much in my sport.

12

6. I don't care as much about my sport

1 performance as I used to.

7. I am not performing up to my ability 1 in my sport.

8. I feel "wiped out" from my sport.

9. I'm not into my sport like I used to be.

10. I feel physically worn out from my sport.

11. I feel less concerned about being 1 successful in my sport than I used to.

12. I am exhausted by the mental and 1 physical demands of my sport.

13. It seems that no matter what I do, I 1 don't perform as well as I should.

14. I feel successful at my sport.

15. I have negative feelings toward my sport. 


\section{Appendix D}

\section{Participant information and Assent Form}

1. I understand that this study in being conducted to find out how high school varsity athletes perceive themselves, their high school coaches, and their high school team. I also understand that my participation in this study will consist of spending the next 20 minutes filling out a set of questionnaires that will ask me how I feel about myself, my high school coach, and my high school team.

2. I understand that I must be at least 16 years old in order to participate in this study.

3. I understand that it is up to me whether or not I want to fill out these questionnaires. If I don't want to do so, I will not be punished in any way.

4. I understand that once I start filling out the questionnaires I can quit anytime I want to and the information that I already gave will be destroyed.

5. I understand that the answers I give on the questionnaires will be anonymous because I am not being asked to give my name or the name of my school.

6. I understand that by completing the questionnaire packet given to me by the person or persons administering this survey, I have given my assent to participating in this study.

7. I understand that any complaints that I have about my participation in this study can be directed to the Office for the Advancement of Research and Scholarship at Miami University by phone (513-529-3600) or by email (humansubjects@ muohio.edu).

8. Any questions that I have about the study can be directed to:

Dr. Thelma Horn

KNH Department

Miami University

Oxford, OH 45056

(513) 529-2723

email: hornts@muohio.edu 
Appendix E

\section{MIAMI UNIVERSITY HIGH SCHOOL ATHLETES RESEARCH PROJECT Summer, 2010 \\ Principal Investigators: Thelma S. Horn and Eric Martin Sports Camp Director Agreement to Participate Form}

1. I understand that this study in being conducted to find out how high school varsity athletes perceive themselves, their high school coaches, and their high school team. I also understand that the athletes in my camp who participate in this study will be asked to spend 20 minutes filling out a set of questionnaires that will ask them how they feel about themselves, their high school coach, and their high school team.

2. I understand that athletes must be at least 16 years old in order to participate in this study.

3. I understand that it is up to the individual athletes as to whether or not they want to fill out these questionnaires. If they don't want to do so, they will not be punished in any way.

4. I understand that once athletes start filling out the questionnaires they can quit anytime they want to and the information that they already gave will be destroyed.

5. I understand that the answers my sports camp athletes give on the study questionnaires will be anonymous because they are not being asked to give my name or the name of their school. I further understand that I, and the members of my sports camp staff, will not have access to (or be allowed to see) the responses provided by the athletes in my sports camp.

6. I understand that athletes in my sports camp who do agree to complete the questionnaire packet given to them by the person or persons administering this survey, will have given their assent to participating in this study.

7. I understand that any complaints that I, or my sports camp participants have about their participation in this study can be directed to the Office for the Advancement of Research and Scholarship at Miami University by phone (513-529-3600) or by email (humansubjects@muohio.edu).

8. Any questions that I have about the study can be directed to:

Dr. Thelma Horn

KNH Department

Miami University

Oxford, $\mathrm{OH} 45056$

(513) 529-2723

email: hornts@muohio.edu

SIGNATURE OF SPORTS CAMP DIRECTOR PRINTED NAME OF SPORTS CAMP DIRECTOR SPORTS CAMP 


\section{Appendix F}

\section{Script \\ (Oral presentation to be delivered to potential study participants prior to data collection session)}

Hello. My name is Eric Martin. I am a graduate student at Miami University in Oxford, Ohio. I am here today to ask each of you to participate in a research study that I, and my academic advisor, Dr. Thelma Horn, are conducting to find out how high school varsity athletes feel about themselves, their sport, their high school coaches' behaviors, and their high school team's level of cohesion. You can only be a participant in this study if you are 16 years or older.

To be a participant in this study, you will need to fill out a series of questionnaires that will ask you how you feel about yourself in different situations and how you evaluate your high school team and coach. Filling out this set of questionnaires should take you about $20-25$ minutes. We are hoping to get 400- 500 high school varsity athletes to fill out these questionnaires. The information we get from this study will tell us what kinds of coaching behaviors and leadership styles are most effective at the high school level.

You should know that no one besides the study investigators will ever see your answers. We are not even asking you to tell us your name. Thus, no one (including ourselves) will be able to identity what answers you, as an individual, provided to our questions. We do hope to write a paper describing the results of this study. This paper would be published in a research journal, but your name and the name of your school would never be identified because we are not even collecting this information.

It is also important for me to tell you that you do not have to participate in this study. That is, if you do not want to fill out the set of questionnaires, you do not have to do so. In addition, if you do begin filling out the questionnaires and decide that you do not want to continue, you can hand back your questionnaire packet to the person administering this survey. Your packet will then be shredded and not used in this study.

In order for you to participate in this study, you will need to read the participant information and assent form I just handed to you, and once you have read this form and are willing to participate in our study, then one of us will give you a questionnaire packet. You should keep the participant information and assent form for yourself. 


\section{Appendix G}

Coaches Letter

Coaches,

Hello, my name is Eric Martin and I am a graduate student at Miami University in Oxford, Ohio. I am writing to you today to ask for your help. In collaboration with my academic advisor, Dr. Thelma Horn, I am conducting my master's thesis on high school athletes. I hope through examination I can better understand the high school sporting experience and I hope come up with information on how to minimize and hopefully prevent burnout in sports.

The survey looks at various intrapersonal and environmental characteristics and how they interact in causing burnout in athletes. The characteristics investigated in this study are passion for their sport, athletic identity (how strongly they feel sport is a part of their core identity), motivational climate, perfectionism and strategies coaches employ to build confidence in their athletes.

If you do decide to allow your athletes to participate in this study no one besides the researchers will ever see your athletes' responses. The survey includes no identifying information and no responses will be linked to an individual athlete. No one (including myself) will be able to identify your players based on their responses on the surveys. Once the surveys are returned we will group them in a larger sample and all information identifying the area, team, and athlete will be eliminated. Once data collection is completed I hope to write a paper describing the results of the study and the paper will be published in a research journal; however your name, the name of your school, and the name of your athletes will never be identified.

Due to confidentiality of the surveys, coaches of the team are not allowed to administer the surveys. Therefore if you do agree to participate in the research I will need to set up a time that myself, or an individual outside of the team, can administer the surveys to your team. If you do agree participate it does not mean that your entire team must fill out the survey. Participation in the survey is completely voluntary and if there are individuals who do not wish to participate they may be excluded. Also due to Institutional Review Board policies the survey is intended for athletes aged 16 and older.

Thank you for your consideration. If you have any questions or need to contact me my phone number is 970-371-6493 or my email is martine5@muohio.edu.

Eric Martin

Kinesiology and Health

Miami University 